\title{
Telemedicine: Current State and COVID-19 Lessons
}

\section{目 Mikhail Zhuravlev}

Research Fellow, Lecturer, Law Faculty, National Research University Higher School of Economics. Address: 20 Myasnitsky St., Moscow 101000, Russia. E-mail: mzhuravlev@hse.ru

\section{凡目 Olga Blagoveshchenskaya}

MA Student, Institute of Economics and Management, National Research Tomsk State University. Address: 36 Lenin Ave., Tomsk 634050, Russian Federation. E-mail: 895280755550@ gmail.com

\section{昰圆 Abstract}

The pandemic is a watershed event that has prompted both an evaluation of the achievements of information and communications technology (ICT) and also a re-evaluation of the prospects for developing social processes compatible with ICT. Much has been already been accomplished in Russia and throughout the world. But in the current pandemic, telemedicine is facing new challenges. This article discusses the state of the art in telemedicine and the prospects for its development in the changing conditions wrought by the pandemic. Examples are provided of the solutions that telemedicine can offer in such a difficult period, and the risks due to widespread use of telemedicine are analyzed. The impact of telemedicine is extensive with consequences for technology, management, and law. This article is a multidisciplinary study of telemedicine from the perspective of management and law. The article examines how telemedicine technologies have been implemented and developed, the obstacles to telemedicine's advance in various countries, and the legislative frameworks that governs it. The article's interdisciplinary study is based on an integrated methodology which combines: a formal logical approach to analysis of the legislation concerning telemedicine; a comparison of the development of telemedicine across several countries; and a sociological method to identify the attitude of Russian medical staff toward telemedicine and its impact. Although telemedicine has been developed and regulated separately by each country, there are general development trends, such as collection and analysis of electronic health records (EHR), devices and systems to simplify communication between doctors and with chronically ill patients, and others. Legislation is one of the significant barriers to the development of telemedicine in different countries. However, the pandemic has been a catalyst for legislative change, and it is precisely those changes that will eliminate the key problem in telemedicine that beset Russia where telemedicine now resembles separate pieces in a puzzle.

\section{O-1国 Keywords}

telemedicine, e-health, COVID-19 pandemic, personal data, electronic health records, cybersecurity, electronic document management, Big Data. 
For citation: Zhuravlev M.S., Blagoveshchenskaya O.K. (2020) Telemedicine: Current State and COVID-19 Lessons // Legal Issues in the Digital Age, no 2, pp. 93-143.

DOI: $10.17323 / 2713-2749.2020 .2 .93 .143$

\section{Introduction}

The advances in telemedicine during recent decades have encouraged hope for reform of healthcare. The purpose of this article is to understand what the future holds for telemedicine in Russia after the pandemic. To do this, the current state of telemedicine, technological trends in it, and the barriers it is encountering have been analyzed along with the options for use of telemedicine during the COVID-19 pandemic and the distinctive features of Russian medicine in in general.

The pandemic has presented us with a fresh way to assess the importance of telemedicine and given us a test of its effectiveness in stressful circumstances. Healthcare systems will evolve faster in 2020 in order to adapt to new needs and to new opportunities for those who are willing to do more to attract healthcare consumers. These systems will reduce the time patients spend waiting to contact doctors and the time doctors spend gaining the confidence of their patients.

Partnerships between healthcare organizations and technology companies will progress rapidly after 2020 as healthcare providers will increasingly focus on innovative technologies and more competitive strategies to attract patients. Major players in the technology market will also concentrate more attention on healthcare and work closely with major healthcare providers and insurers to develop new technologies that will improve the quality of patient care.

\section{Global Overview of Telemedicine}

\subsection{How Telemedicine is Defined}

Which of telemedicine's particular features legislation incorporates in the legal concept of it is of paramount importance when telemedicine is introduced into a country and in choosing the path for its development. It should come as no surprise that the legislation of each country offers up its own concept of telemedicine.

The definition of telemedicine in the USA is established by each of its constituent state governments, although they base the definition on remote 
provision of medical services using electronic means of communication to exchange data. For example, the Alaska State Administrative Code ${ }^{1}$ defines telemedicine as "the practice of health care delivery, evaluation, diagnosis, consultation, or treatment, using the transfer of medical data through audio, video, or data communications that are engaged in over two or more locations between providers who are physically separated from the patient or from each other." The essential elements in this definition are: 1) the provision of medical services; 2) the use of communications for data transmission; 3 ) the remote nature of the interaction.

Telemedicine functions in the United States are regulated by the laws of each state in a special act on telemedicine ${ }^{2}$ or in several acts devoted to certain aspects of telemedicine (licensing, insurance, etc.) ${ }^{3}$. Different US states have different approaches to the legalization of various telemedicine activities. Some states quickly recognized the potential for remote diagnosis and treatment, while other states took many years to do this, and in some states certain forms of telemedicine activity are still not legal ${ }^{4}$.

US law on telemedicine is exceptionally diverse because each US state makes its own legislation, which means each state can impose its own detailed understanding of what telemedicine is. In Massachusetts law, telemedicine is defined as the provision of healthcare services using interactive audio, video, or other electronic communications for diagnostic, counseling, or treatment purposes. But in Massachusetts telemedicine does not include services that use only the telephone, facsimile or email ${ }^{5}$.

1 Alaska Admin. Code. Title 7, 12.449, quoted in State Telehealth Laws \& Reimbursement Policies. Available at: https://www.cchpca.org/sites/default/files/2019-05/cchp_report_MASTER_ spring_2019_FINAL.pdf (accessed: 01.07.2020)

2 New Jersey's telemedicine law: What providers need to know, a commentary on the website of the Foley and Lardner LLP legal practice. Available at: https://www.healthcarelawtoday.com/2017/08/07/new-jerseys-telemedicine-law-what-providers-need-to-know/ (accessed: 01.07.2020)

3 Current State Laws \& Reimbursement Policies, Center for Connected Health Policy. Available at: https://www.cchpca.org/telehealth-policy/current-state-laws-and-reimbursement-policies (accessed: 01.07.2020)

${ }^{4}$ Regulatory approaches to telemedicine, General Medical Council. Available at: https://www. gmc-uk.org/about/what-we-do-and-why/data-and-research/research-and-insight-archive/regulatory-approaches-to-telemedicine (accessed: 01.07.2020)

5 Annotated Laws of Massachusetts. Chapter 224, Sec. 158, State Telehealth Laws \& Reimbursement Policies. Available at: https://www.cchpca.org/sites/default/files/2019-05/cchp_report_MASTER_spring_2019_FINAL.pdf (accessed: 01.07.2020) 
A recent trend in the United States is to expand the concept of telemedicine. For example, in Arkansas ${ }^{6}$, a 2015 law defines telemedicine as the use of electronic information and communication technologies to provide healthcare services, including and without limitation diagnosis, counseling, treatment, education, healthcare administration and patient self-management; telemedicine also extends to store-and-forward processing of medical information and remote monitoring of patient health. The Arkansas definition is not limited to the exchange of data for the provision of remote medical services, as it includes matters related to data storage and transfer, administration, education, etc.

The American Telemedicine Association (ATA) is now taking a broader approach to the definition of telemedicine. The terms "telemedicine" and "telehealth" are used by the ATA as synonymous, encompassing "technology-based service delivery and healthcare management that increase opportunities and accessibility". ATA notes that with the development of information technologies such as artificial intelligence and virtual reality, the concept of telemedicine is expanding even more ${ }^{7}$.

The European Union (EU) in theory and in legal documents uses the term "telemedicine" along with the term "e-health". The European Commission defines telemedicine as:

...the provision of health services, through the use of ICT, in situations where the health professional and the patient (or two health professionals) are not in the same location. It involves secure transmission of medical data and information, through text, sound, images, or other forms needed for the prevention, diagnosis, treatment and follow-up of patients ${ }^{8}$.

This definition implies a distinction between two types of telemedicine: 1) services involving medical action, such as interpreting X-ray images; 2 ) telemonitoring, which refers to remote monitoring of health status. However, neither electronic health records, nor electronic prescriptions, nor

${ }^{6}$ Arkansas Code Sec. 17-80-402, State Telehealth Laws \& Reimbursement Policies. Available at: https://www.cchpca.org/sites/default/files/2019-05/cchp_report_MASTER_spring_2019_FINAL. pdf (accessed: 01.07.2020)

7 Available at: https://www.americantelemed.org/resource/why-telemedicine/ (accessed: 01.07.2020)

${ }^{8}$ Report of the eHealth Stakeholder Group on implementing the Digital Agenda for Europe Key Action 13/2 'Telemedicine', an official website of European Union. Available at: http://ec.europa.eu/ information_society/newsroom/cf/dae/document.cfm?doc_id=5167 (accessed: 01.07.2020) 
electronic referrals are regarded as part of telemedicine in the EU although they are part of e-health.

The European approach to the definition of telemedicine is narrow and comes down to providing medical services through data transmission. In this understanding, telemedicine is part of e-health, which is a combination of "tools and services that use information and communication technologies to improve the prevention, diagnosis, treatment of diseases, monitoring and administration in the field of healthcare". E-health covers the following areas: electronic document management between patients, medical organizations and doctors; telemedicine services; portable devices for monitoring patient health; planning software; robotic surgery, etc. ${ }^{9}$

The Russian equivalents of "e-health" and "telemedicine" are also somewhat vaguely defined. Earlier legal sources ${ }^{10}$ use the terms "telemedicine technologies" and "internet medicine". Telemedicine technologies include diagnostic and treatment consultations and also managerial, educational, scientific and educational activities in the field of healthcare that are implemented using telecommunication technologies, Internet medicine is regarded as an integral part of telemedicine technologies and includes information support for clinical medicine in counseling patients; health service referrals; providing access to library databases, etc.

The Russian Health Fundamentals Act of $2017^{11}$ introduced a new definition for telemedicine technologies, which came to be understood as information technologies that ensure remote interaction of medical workers with each other, with patients and (or) their legal representatives, identification and authentication of these persons, documentation of their actions during consultations, and remote medical monitoring of a patient's health. Although Russian legislation does not provide a legal definition of telemedicine like the European one, the use of telemedicine technologies is subject to legal regulation.

9 Communication from the Commission to the European Parliament, the Council, the European Economic and Social Committee and the Committee of the Regions on telemedicine for the benefit of patients, healthcare systems and society, European Union Law. Available at: http://eur-lex. europa.eu/LexUriServ/LexUriServ.do?uri=COM:2008:0689:FIN:EN:PDF (accessed: 01.07.2020)

${ }^{10}$ Ministry of Health of the Russian Federation. Order N 344, RAMS N 76 dated 27 August 2001 "On approval of the Concept for the development of telemedicine technologies in the Russian Federation and its implementation plan"/ Consultant Plus.

${ }^{11}$ Federal Law dated 29 July 2017 No. 242-FZ "On amending certain legislative acts of the Russian Federation on the use of information technologies in the field of health care", SZ RF. 31 July 2017, N 31 (Part I), Art. 4791. 
It seems that a restrictive understanding of telemedicine in both Russian and foreign law has been mostly provisional because regulating interaction through telemedicine inevitably overlaps with other matters related to e-health, including health information systems, electronic health records, electronic prescriptions, etc. The concepts of telemedicine and e-health seem to be converging.

A 2007 World Health Organization (WHO) study identified 104 definitions of telemedicine ${ }^{12}$. To remedy the ambiguities in the definition of telemedicine, WHO has proposed using the terms "telemedicine" and "e-health" as synonymous in a broad sense ${ }^{13}$. In 2005, WHO defined ehealth as "the cost-effective and secure use of information and communications technologies in support of health and health-related fields, including health-care services, health surveillance, health literature, and health education, knowledge and research"14. This way of framing e-health goes beyond the use of information technology to provide medical services directly and create the necessary infrastructure to do so by also including such areas as providing access to medical literature using ICTs, promoting a healthy lifestyle through e-learning, etc. The International Telecommunication Union follows a similar approach ${ }^{15}$. For the purposes of pursuing state policy in the field of health information, a broad approach of this kind seems very suitable for guiding governmental policy concerning healthcare that is mediated by digital information because it leaves room for a comprehensive consideration of the all the issues that need to be addressed.

It should be noted that in addition to the terms "e-health" (and sometimes "telehealth") and "telemedicine", other terms such as "mobile health" (or "Mhealth"), "electronic medicine" ("e-medicine"), interactive medicine and more are in use. By and large, they refer to the same concepts but are used in some situations to emphasize one aspect or another of e-health. For

12 Telemedicine. Opportunities and development in member states. WHO report on the results of the second global survey in e-health, World Health Organization, p. 9. Available at: http://apps. who.int/iris/bitstream/10665/87687/1/9789244564141_rus.pdf (accessed: 01.07.2020)

${ }_{13}$ WHO Resolutions and Decisions. eHealth, World Health Organization. Available at: http:// apps.who.int/iris/bitstream/10665/20378/1/WHA58_28-en.pdf (accessed: 01.07.2020)

${ }_{14}$ WHO Resolutions and Decision. Available at: https://apps.who.int/iris/bitstream/handle/10665/20378/WHA58_28-en.pdf;jsessionid=B45030782058B782F7C39CDDA68FBC00?seque nce $=1$ (accessed: 01.07.2020)

15 ITU-T SG 16 Work on E-health - Definition of some terms related to e-health technologies, International Telecommunication Union. Available at: https://www.itu.int/en/ITU-T/studygroups/2013-2016/16/Pages/ehealth_terminology.aspx (accessed: 01.07.2020) 
example, the term "mobile health" is used to single out telemedicine based on wireless devices and mobile phones by emphasizing certain of the means for carrying out telemedicine. However, the particular means used in telemedicine do not have great legal significance. This is consistent with the principle that legal regulation should be technologically neutral.

For the purpose of this study it will be useful to condense all the concepts considered so far into the single term "telemedicine" which refers to the use of information and communication technologies for the provision of medical services, the creation and maintenance of a healthcare infrastructure, and improvement in the quality and accessibility of healthcare. In this sense, telemedicine includes health information systems, electronic patient health records, remote medical services, remote monitoring of patient health status, access to electronic documents (prescriptions, sick leave documentation, medical reports and certificates), electronic appointments with doctors, remote medical consultations and other forms of medical activity including medical research involving information and communication technologies. The defining features of telemedicine are the remote nature of the interaction between the participants in telemedicine activities and automated processing of information. Telemedicine and e-health will be used synonymously and interchangeably. A similarly broad approach to defining telemedicine is supported in Russian legal literature and has been prompted by the need to identify general trends in the application of information technologies to medicine and in their legal regulation [Putilo N.V. \& Volkova N.S., 2018: 124-135].

Putilo and Volkova suggest that telemedicine be understood as a system for exchanging medical information through information and communication technologies and that it consist of the following elements: 1) training tools for medical workers (teleconferences, training programs, online training, etc.); 2) ways of transmitting information as part of patient counseling; 3) means for electronic interaction between participants in the healthcare system (electronic cards, electronic records, electronic prescriptions); 4) electronic means for monitoring the patient's health with direct surveillance of the patient by an agent in the information system or by the attending physician (e.g., via an electronic bracelet); 5) a special information environment (special sites created by public organizations to inform and advise patients and medical workers); 6) online sales of medicines and medical devices.

The concept of telemedicine is dynamic, and over time it will respond to new technological advances and changing health needs and also adapt to 
new and changing social contexts. Thus, it is possible that new technologies will need to be included in the definition of telemedicine. For example, in Russia the concept of telemedicine had not previously included the delivery of medications but now does include it.

\subsection{Telemedicine Law and Policy in Different Countries}

As they understand the tremendous importance of information technology in modern society, many national governments are now pursuing a policy of comprehensive digital transformation or ways to relate to the public. Establishing e-health is one of the important goals for that kind of transformation.

Providing a high-quality and reliable IT infrastructure is important, but it is not the only element necessary for successful advancement of e-health. Some countries with relatively high rates of penetration of information technologies (access to broadband internet, mobile coverage, a high number of personal computers and mobile devices per capita and other similar indicators) are still lagging behind in developing e-health. For example, a study of e-health among EU countries found that Bulgaria is one of the most advanced EU countries in deploying information and communication technologies although it is far behind in developing e-health [Currie W. \& Seddon J., 2014: 783-797]. One of the main reasons for Bulgaria's falling behind is lack of a national strategy for applying information and communication technologies to healthcare, including lack of regulation for it.

Telemedicine is definitely a field that requires governmental regulation because it must have high safety standards and protect the rights of patients, etc. The United States serves as an example of the inadequacy of market mechanisms to advance telemedicine. Although the e-health market, including electronic medical records and remote medical services, came about in the United States at the behest of economic actors (medical organizations and insurance companies) rather than because of any government prompting [Carlisle G. et al., 2013: 51], the need for government intervention in shaping the market for telemedicine services very soon became evident, mainly in matters of licensing, insurance, and protection of patients' personal data.

Many countries are adopting strategies and developing legislation to remove legal barriers to using digital technologies in various areas of interacting with the public, including in healthcare. 
In the European Union the key strategic document aimed at universal digitalization of European society is the Digital Agenda for Europe ${ }^{16}$, which is part of the broader EU development strategy through 2020 (Europe 2020) ${ }^{17}$. Effective use of digital technology to improve the quality of healthcare is one of the goals of this strategy. For telemedicine the Digital Agenda emphasizes the importance of ensuring trust and security because it cannot exist without reliable and trustworthy information technologies (Section 2.3). An important condition for the success of e-health is to ensure that patients may safely store their personal health records in health information systems that are available online (Section 2.7.2). The strategy states that the realization of the full potential of information technology in healthcare requires removing legal and organizational barriers, as well as strengthening cooperation between EU member states, in order to form a single market for digital services including telemedicine services. The document states that the potential of ICT can help solve important problems for the EU such as an aging population, increasing healthcare costs, and integrating people with disabilities into society.

More specific steps for the development of e-health in the EU were set forth by the first Action Plan for the Development of eHealth for 2004-2011 (eHealth Action Plan 2004-2011) ${ }^{18}$ and also developed after the adoption of the Digital Agenda by the second Action Plan for 2012-2020 (eHealth Action Plan 2012-2020) ${ }^{19}$. The first Action Plan mainly covered ways to implement electronic prescriptions and electronic maps and to ensure interaction between health information systems. The second Action Plan was focused on implementing the provisions of EU Directive 2011/24/EU on

${ }^{16}$ Communication from the Commission to the European Parliament, the Council, the European Economic and Social Committee and the Committee of the Regions A Digital Agenda for Europe, European Union Law. Available at: http://eur-lex.europa.eu/legal-content/EN/ ALL/?uri=CELEX\%3A52010DC0245 (accessed: 01.07.2020)

17 EUROPE 2020 A strategy for smart, sustainable and inclusive growth, European Union Law. Available at: http://eur-lex.europa.eu/legal-content/EN/TXT/?uri=celex:52010DC2020 (accessed: 01.07.2020)

18 Communication from the Commission to the Council, the European Parliament, the European Economic and Social Committee and the Committee of the Regions - e-Health - making healthcare better for European citizens: an action plan for a European e-Health Area. Available at: http://eur-lex.europa.eu/legal-content/EN/ALL/?uri=CELEX:52004DC0356 (accessed: 01.08.2019)

19 Communication from the Commission to the Council, the European Parliament, the European Economic and Social Committee and the Committee of the Regions - eHealth Action Plan 2012-2020 - Innovative healthcare for the 21st century. Available at: http://eur-lex.europa.eu/ legal-content/EN/ALL/?uri=CELEX:52012DC0736 (accessed: 01.08.2019) 
the application of patients' rights in cross-border healthcare ${ }^{20}$, which sought to enhance cooperation between EU member states in order to maximize the social and economic benefits of e-health development throughout the Union. The second Action Plan builds upon the progress achieved, but it acknowledges that significant barriers still remain in the path to full implementation of e-health.

While the first stage of establishing e-health in the European Union was aimed at creating an e-health information infrastructure, the second stage is already directly involved in organizing telemedicine services as well as the use of modern information technologies to improve the quality of healthcare. Hence, one of the key goals of the second Action Plan is to stimulate research through telemedicine technologies (Section 5.1). The European Commission recognizes the importance of health research and innovation in both the short and long term. Information technology and science can have a synergistic effect and contribute to improving the effectiveness of healthcare. To support research and innovation in e-health, the development of various forms of public-private partnerships and government funding of e-health research projects has been proposed.

Within EU member states some aspects of telemedicine are regulated by national legislation on health protection and other legislative acts ${ }^{21}$. Some countries have adopted separate laws on telemedicine. For example, Germany in 2016 passed a law on secure digital communications and software in the healthcare system ${ }^{22}$, which establishes the legal framework for handling electronic patient health records, health information systems and electronic document management in the healthcare system when providing telemedicine services.

German federal law does not prohibit making a diagnosis and prescribing therapy remotely and permits them at any time convenient for the patient rather than only during usual reception hours. By May 2018 legislative

${ }^{20}$ Directive 2011/24/EU of the European Parliament and of the Council of 9 March 2011 on the application of patients' rights in cross-border healthcare. Available at: https://eur-lex.europa.eu/ legal-content/EN/TXT/?uri=CELEX\%3A32011L0024 (accessed: 01.08.2019)

${ }^{21}$ Overview of the national laws on electronic health records in the EU Member States and their interaction with the provision of cross-border eHealth services. Final report and recommendations, European Union. Available at: https:/ec.europa.eu/health/sites/health/files/ ehealth/docs/laws_report_recommendations_en.pdf (accessed: 01.07. 2020)

${ }^{22}$ E-Health law in Germany, a commentary by the Taylor Wessing legal practice. Available at: https://www.lexology.com/library/detail.aspx?g=83f3f929-7be7-4383-a66b-ed1dedeb912d (accessed: 01.07.2020) 
restrictions on remote diagnoses had been removed with the caveat that a remote diagnosis can be made if there is objective evidence for it. At present a ban on prescribing treatment remotely has been retained only in states of Brandenburg and Mecklenburg-Vorpommern [Wernick A. \& Klünker I., 2019: 169-177].

In contrast to the countries of the European Union, the USA has no uniform strategy for developing telemedicine and e-health.

The United States regulates a small range of issues pertaining to telemedicine at the federal level. In 1996 the United States passed the Health Insurance Portability and Accountability Act (HIPAA) ${ }^{23}$, one of whose provisions set requirements for the confidentiality and security of personal health information about patients in electronic form. In 2009 the Health Information Technology for Economic and Clinical Health Act (HITECH Act) ${ }^{24}$ introduced a government incentive program for the introduction of electronic health records (EHRs). The law entitled physicians who use information technologies to improve medical services (meaningful use) to receive a government subsidy of up to US\$63,750 under certain conditions.

The regulation of most issues, such as licensing requirements for doctors, liability issues, health insurance, and a number of other aspects of telemedicine, falls within the purview of each individual state government. Even the federally enacted HIPAA does not ensure the uniformity of state regulations in protecting patient data because states have the option to apply stricter rules for such data when processed by information systems. All this creates additional barriers to the development of telemedicine throughout the United States.

\subsection{Electronic Health Records, Data Sharing and Resistance to Telemedicine}

Up until 2019 and before the pandemic, the electronic health record (EHR), which is already being used by Austria, France, Israel, Japan, Singapore, Estonia, Finland, Slovakia, Spain and Sweden had been the focus of development in telemedicine. EHR is also in place partially, but not everywhere in the UK and in its public hospitals.

${ }^{23}$ Health Insurance Portability and Accountability Act of 1996, US Congress. Available at: https://www.congress.gov/104/plaws/publ191/PLAW-104publ191.pdf (accessed: 01.07.2020)

${ }^{24}$ What is the HITECH Act?, HIPAA Journal. Available at: https://www.hipaajournal.com/ what-is-the-hitech-act/ (accessed: 01.07.2020) 
An EHR system typically consists of data protection features, information received by doctors, and establishment of a unified set of terms and common standards.

The telemedicine services market has made the most advances in the USA, and as a result information systems there are increasing their integration into healthcare more than in the rest of the world. The HITECH Act (Health Information Technology for Economic and Clinical Health Act) ${ }^{25}$ in the United States was providing government incentives for introducing EHR as early as 2009.

A study by Grand View Research showed that the global EHR market in 2016 amounted to US $\$ 23$ billion and that by 2025 it would increase to US $\$ 33$ billion. Most of this amount is concentrated in the USA where companies like Epic have dominated the EHR systems market (at 26.7\% in 2016), while Cerner (24.8\%), Meditech (17\%) and Centricity Practice Solution (10.3\%) together accounted for almost half of the market ${ }^{26}$.

In addition, the U.S. Department of Health and Human Services and the National Institute of Standards and Technology are involved in the development, support and standardization of digital medicine, while Brazil, India, Russia and Asian countries are also actively developing it.

EHRs can contain a complete history of people who visit various medical institutions, including test and immunization charts as well as data on allergies and all illnesses. This allows doctors to quickly obtain comprehensive information about patients and more accurately prescribe treatment and at the same time reduces the amount of paperwork.

The EHR has become a key to the development of telemedicine because of the advantages it offers. One primary and very important benefit is security: patient status data is archived safely in a secure cloud storage system. This ensures that complete information about all the illnesses and individual characteristics of patients will not be lost or misplaced and will be available in any treatment facility. This method of data storage includes proper encryption and is extremely reliable because it is relatively invulnerable to external physical factors such as a physical server's malfunction or failure.

Another feature of EHRs is that the records contain a history of changes in the patients' condition throughout their lives. The doctor can see the pa-

25 Ibid.

${ }^{26}$ Digital medicine as a way to reduce healthcare paperwork, a presentation at the M-Health Congress. Available at: https://mhealthcongress.ru/en/article/tsifrovaya-meditsina-kak-sposobsokratit-bumagnuyu-rabotu-v-sfere-zdravoohraneniya-96477 (accessed: 29.04.2020) 
tient's reaction in the past to various therapies, and this information will help indicate the most suitable treatment in the current situation. Complete information with immediate access to it will help doctors conduct better analyses and make more accurate diagnoses.

Systematic information stored in digital form instead of on paper permits medical organizations to make research both broader and more refined. This is especially helpful with statistics concerning diseases.

EHRs can be used to implement programs for controlling the quality of healthcare in a country, and it can also facilitate use of digitized data derived from older paper records in the database in order to make more accurate forecasts based on this retrospective big data.

For the patient an EHR makes it easier to choose from among a broader range of doctors and specialists without being tied to one medical institution.

In different jurisdictions two legal arrangements for creating electronic health records have become widespread - opt-in and opt-out ${ }^{27}$. The opt-in provision (used in France and until 2016 in Australia) involves obtaining prior consent from patients to create EHRs and distribute them through health information systems. The opt-out provision (used since 2016 in the UK, Singapore, Australia, etc.) involves creating EHRs without consent from patients although they retain the right to have them removed after they have been created.

The opt-in arrangement is designed to increase the autonomy of patients by having them make an informed choice to participate in the electronic exchange of medical information. The use of the opt-in method accords a higher degree of responsibility to patients themselves for their choice, including the choice of which person or organization they trust to store and manage their personal electronic health records. Despite the opt-in method's obvious positive features, it has a significant drawback in that it complicates the process of creating a unified field information for telemedicine, does not ensure that complete information on all patients in the system will be available and leaves all the medical data of a potentially large number of patients who do not opt in outside of electronic document management.

The opt-out mechanism permits electronic records on patient health to be created without their consent, but they can reject retention of their elec-

${ }^{27}$ EHR Systems-Opt in or opt out?, a commentary by the Accenture consulting firm. Available at: https://www.accenture.com/es-es/ /media/Accenture/Conversion-Assets/DotCom/Documents/Local/es-es/PDF_3/Accenture-Health-Opt-In-Opt-Out.pdf (accessed: 29.04.2020) 
tronic records and exclude them from electronic document management. This method comes under criticism for ignoring the preferences patients may have about the creation and handling of EHRs. However, the opt-out method has the best potential for keeping greatest possible amount of medical information under electronic document management and ensuring the completeness of the information stored in healthcare information systems. The benefits of having more medical information in electronic document management persuaded Australia after 2016 to replace the opt-in mechanism with opt-out (with a two-year period during which refusal to participate is permitted $)^{28}$.

In some countries, such as the USA ${ }^{29}$ and Singapore ${ }^{30}$, legislation establishes the obligation of medical organizations to create electronic records of patient health, but it still grants patients the right to refuse retention of electronic records.

The legislation of various countries shows a general preference for the compulsory creation of EHR, but the right of patients to refuse to include their personal health records in the electronic document management system is recognized. In what follows most of the comparative statistics concerning penetration of telemedicine and attitudes toward it in different countries is taken from surveys of 15,000 patients and 3,100 healthcare professionals in 15 countries. These surveys were commissioned and published by the Philips multinational corporation in an effort to assess the global market for telemedicine solutions and promote its advance.

The penetration of telemedicine and its subsystems can vary broadly among countries and even within a single country. While $84 \%$ of healthcare professionals in the USA use EHRs, only $46 \%$ of USA healthcare professionals use the full range of telemedicine, compared to a 15-country average of $61 \%$; and only about $33 \%$ use AI-powered solutions in their practice or hospital ${ }^{31}$.

${ }^{28}$ See the webpage description My Health Record posted by the Office of the Australian Information Commissioner (OAIC). Available at: https://www.oaic.gov.au/privacy-law/other-legislation/ my-health-records (accessed: 29.04.2020)

${ }^{29}$ HHS: Everyone can opt out of government-mandated electronic health records system, CNS News. Available at: https://www.cnsnews.com/news/article/hhs-everyone-can-opt-out-government-mandated-electronic-health-records-system (accessed: 29.04.2020)

${ }^{30}$ Greater protection of patient data when national electronic medical records become mandatory, The Straits Times. Available at: https://www.straitstimes.com/singapore/health/greater-protection-of-patient-data-when-national-electronic-medical-records-become (accessed: 29.04.2020)

${ }^{31}$ Future Health Index 2019. Available at: https://www.usa.philips.com/c-dam/corporate/newscenter/global/future-health-index/fhi2019/fhi-2019-report-united-states.pdf (accessed: 29.04.2020) 
These indicators suggest that despite the increased use of AI techniques, which are viewed as the gateway to the next phase of telemedicine, the general acceptance of new technologies and solutions is lagging. Innovation in fields like healthcare and education is usually a long and difficult process even when its advantages are clear; and these statistics support that idea.

Countries like Germany (41\%) and China (85\%) surpass the U.S. in the use of AI technologies among healthcare professionals, even though the U.S. has one of the highest costs for use of AI for preliminary diagnoses per capita at US\$ 0.06 , while China's cost is US\$ 0.002 per capita and Germany's is US\$ 0.03 per capita ${ }^{32}$.

This once again confirms that a high level of technological development, for AI in this case, does not directly ensure its implementation in such areas as healthcare.

The public still has questions about the introduction of EHR, and US healthcare professionals have not enthusiastically embraced EHRs, as a common assumption among healthcare professionals is that making these records adds administrative tasks to their workload and reduces time with patients. Healthcare professionals in the US using EHRs were among the most likely to believe that the adoption of EHRs in their hospital or practice had a negative impact on time spent with a patient (53\%), healthcare professional workload (61\%) and healthcare professional satisfaction $(44 \%)^{33}$. These data are not merely concerns about future impact; they are a direct reaction to the systems that medical staff are actually using.

Introducing EHRs can also prompt resistance to them. In the Asian countries surveyed for the Future Health Index, healthcare professionals who do not share patient data outside their healthcare facility cite data privacy and security concerns as key reasons for their reluctance. Among European countries the Future Health Index surveys found interoperability and lack of access were more prominent objections.

Technology continues to evolve, and this will in turn drive continuous transformation in health systems around the world. Healthcare professionals that embrace the use of digital health technology are seeing a positive

32 Transforming healthcare experiences, Future Health Index 2019. Available at: https://images.philips.com/is/content/PhilipsConsumer/Campaigns/CA20162504_Philips_Newscenter/ Philips_Future_Health_Index_2019_report_transforming_healthcare_experiences.pdf (accessed: 29.04.2020)

33 Ibid. 


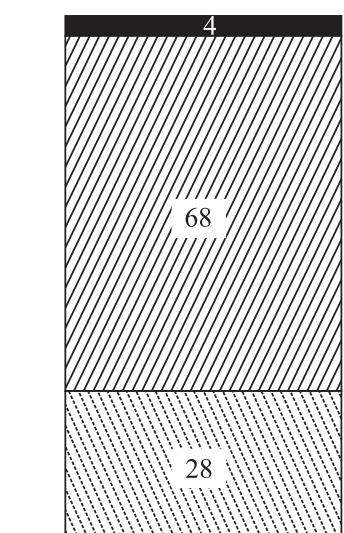

China

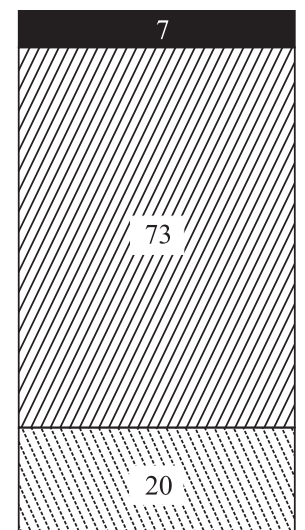

Singapore
8

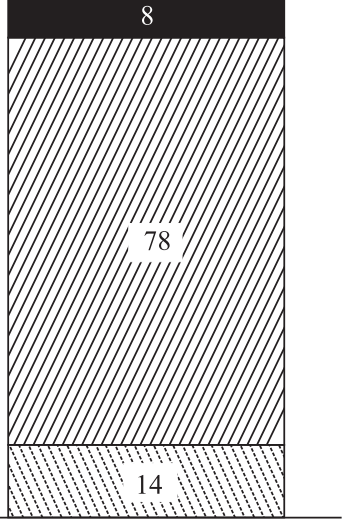

15-country average

Don't know

$\square$ Do not feel threatened by new advancements in healthcare technology

Feel their long-term job security is threatened by new advancements in healthcare technology

Fig. 1. Telemedicine Barriers (China, Singapore, 15-country average), $\%^{34}$

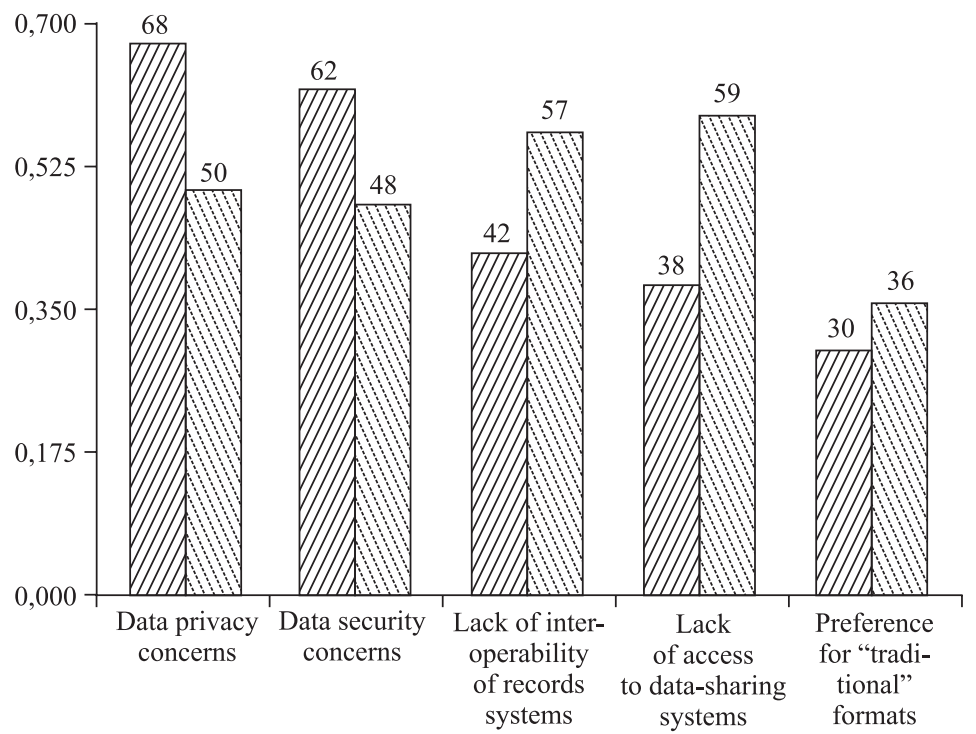

$\square$ Asian countries

Fig. 2. Telemedicine Barriers (Asian and European countries), $\%^{35}$

\footnotetext{
${ }^{34}$ Ibid.

35 Ibid.
} 
impact on their own experience as well as on that of their patients. Digitally empowered patients who share their health data tend to have a stronger relationship with healthcare professionals. The forerunner countries that have leapfrogged over others in their adoption of digital health technology have solved many of the challenges that others are still grappling with, but they face new obstacles that come with the advanced use of digital health technology.

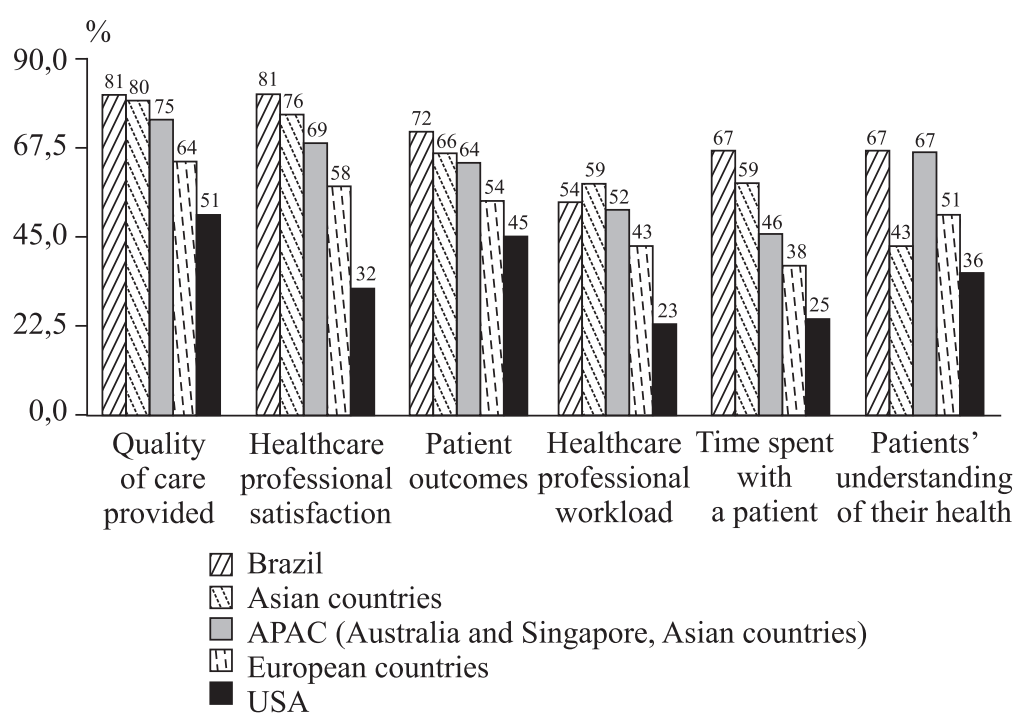

Fig. 3. Use of EHRs by medical staff from different countries ${ }^{36}$

While the forerunners have been moving steadily ahead with digital healthcare technologies, barriers to broader adoption remain. European countries especially stand out in the Future Health Index surveys: lack of access to data-sharing systems (of greater concern than in the Asian forerunners by $15 \%$ ), lack of interoperability of records systems (of greater concern by $21 \%$ ), preference for 'traditional' formats (more of a factor by $6 \%$ ). The surveys also show that data privacy concerns (18\% more prevalent than in European countries) and data security concerns (14\% more prevalent) are greater drawbacks in Asian countries ${ }^{37}$.

The aforementioned barriers hinder the development of telemedicine in general, even when the population (patients or medical personnel) is al-

\footnotetext{
36 Ibid.

37 Ibid.
} 
ready ready to master the technology, realizing the ever-growing need. The demand for telemedicine may then decrease and prompt a wasteful search for new solutions by patients or medical personnel.

If all the barriers to the development and spread of telemedicine in different countries may be viewed generally without paying too much attention to particular cases, resistance falls into the following main groups:

1. Cultural differences. Some countries are not ready to adapt quickly because the traditional system of interaction with the doctor has developed over the years and decades (for example, the United States with its sophisticated legal system and larger differences between states.)

2. Legal barriers. Legislation is not a catalyst of change (as in Germany) but instead a limiting factor. Although the market may be ready for innovations and sees their beneficial impact, the law holds back (or again as in the USA where a complex legislative system interferes with applying the same measures immediately in all of its states).

3. Suspicion. The misgivings are not usually due to a distrust of technology in itself, which may arise from lack of awareness. Suspicion focuses mostly on the potential for theft of personal data or its improper use.

4. Systemic inconsistency. Medical professionals are often prevented from using all the telemedicine technologies because different software or upgrades do not interact as expected. The users cannot then enjoy the anticipated benefits.

\subsection{Telemedicine Market and Innovations}

The number of professionals using new technologies speaks for the assimilation of these technologies. In the healthcare sector, it is the medical professionals who set the pace for technology adoption and implementation. The very low percentage of healthcare professionals in Germany who currently use any digital health technology or mobile health apps (64\%) is an outlier, given that the average for all countries is $78 \%$. A lower rate is found only in South Africa (48\%).

Such date shows which countries have been moving steadily from merely gaining access to digital health technology to actually implementing it. China, India, Italy and Saudi Arabia (more than 85\%) stand out as consistent forerunners when it comes to the adoption and use of all new technologies ${ }^{38}$.

${ }^{38}$ Ibid. 
Some other emerging markets, including India and Russia, also excel in specific areas. Such countries can be considered "legislators" of development and trends in healthcare technologies.

Although there have usually been some problems in the use of telemedicine technology, it is continuing its rapid development. In 2019 and 2020 many interesting and innovative companies, technologies and applications have appeared. These innovations apply first to medical personnel. Of course, any technologies for improving the quality of doctor-patient interactions are bound to be used by medical personnel as well. But technologies created only for doctors have begun to appear on the market. There is Smartbadge Communicator ${ }^{39}$, a large-screen device that provides access to various medical systems. It allows medical professionals from the same hospital to quickly communicate with each other by voice.

Other technologies augment the skills of medical professionals. One such invention is the Remedy platform ${ }^{40}$ which uses AI. It allows medical personnel who are not qualified as physicians to access medical experience in order to detect hidden chronic diseases when interviewing patients by telephone or video; they can expedite treatment choices by collecting clinically relevant information outside the four walls of the hospital. This kind of early diagnosis helps in determining the best therapy for benefiting the patient's health while keeping costs lower.

There are other innovations that help patients with any illness. For example, Pria ${ }^{41}$ is home care device that reminds patients to take medication, dispenses it and acts as a video call device. Pria can monitor patients and remotely inform the doctor about their condition through a smartphone application.

Chronically ill patients can benefit from devices that constantly monitor important vital signs. The Omron HeartGuide ${ }^{42}$ is a smart watch which accurately measures blood pressure and sends data to a smartphone. The same application works for people with diabetes, asthma and other chronic diseases.

${ }^{39}$ Smartbadge Communicator website. Available at: https://www.vocera.com/vocera-smartbadge (accessed: 29.04 .2020 )

${ }^{40}$ Remedy platform website Available at: https://www.remedyhealthmedia.com/ (accessed: 29.04.2020)

${ }^{41}$ Pria website. Available at: https://www.okpria.com/ (accessed: 29.04.2020)

${ }^{42}$ Omron HeartGuide website. Available at: https://omronhealthcare.com/products/heartguide-wearable-blood-pressure-monitor-bp8000m/ (accessed: 29.04.2020) 
Some devices help patients through everyday life. Heartbit ${ }^{43}$ is a wearable device from Hungary for monitoring a person's ECG, which is then used to devise an effective training program that is suitable for a person's cardiac condition. Sensors are built into training t-shirts so that Heartbit smart algorithms can ward off arrhythmias, ischemia and other hidden heart conditions. A technology like this is an innovative supplement to treatment by a cardiac specialist.

One of the most urgent tasks facing telemedicine is to improve the accuracy of online consultations and simplify the process as a whole. The EYE-SYNC concussion assessment system ${ }^{44}$ using VR glasses with sensors that monitor eye movement has been created to do that for one type of injury, and it can reach a diagnosis in the absence of a doctor. Tyto Care offers remote medical services in the USA, Japan and China. It allows patients to conduct their own medical exam using a device that combines a camera, a stethoscope, an otoscope, a thermometer and a tongue depressor. Tyto can take high-resolution images of moles, rashes, and other skin lesions so that a doctor can make a preliminary dermatological analysis. Other images can be made in order to diagnose optical conditions such as conjunctivitis or eye infections. All information is transmitted directly to a screen on which the doctor sees the whole picture. The Tyto platform also instructs the user by means of a smart guidance system that provides audible and visual cues that help the patient to capture a useful image or sound. There is also a way to save examination data in the cloud so that the doctor can later refer to the results.

Using these technologies yields impressive results [Flodgren G. et al., 2015]; [Moy F. et al., 2019]. Telemedicine technologies are particularly important in regions where there are problems with the availability of medicine, such as being far from a medical institution [Oliveira T. et al., 2012].

A few trends in the development of telemedicine technologies can be discerned after analyzing these innovations. First, there are devices and systems to facilitate communication between doctors and in particular to quickly arrange consultations with more specialized professionals. Second, there are devices that enable chronically ill patients to have the data necessary for analysis or rapid response continuously collected and transmitted

${ }^{43}$ Hungarian Heartbit website. Available at: https://theheartbit.com/ (accessed: 29.04.2020)

${ }^{44}$ EYE-SYNC website Available at: https://syncthink.com/2019/02/19/fda-grants-syncthinkseye-sync-platform-breakthrough-device-designation-for-aid-to-concussion-assessment/ (accessed: 29.04.2020) 
to doctors. This kind of device is for patients with cardiovascular diseases, diabetes, asthma, and persons with mental disorders. Third, there are homeuse devices which increase the effectiveness of online examinations by enabling transmission of data to a doctor. Making online examinations as close as possible to an initial interview in person is especially important here.

Another outcome of all these technologies is the potential for collection and in-depth analysis of medical records and patient histories; this greatly simplifies the work of the doctor and reduces admission times, which is one way to increase the throughput of a specialist or hospital.

Extraordinary developments are appearing on the market horizon, such as robots that can maintain a conversation with elderly patients and track their condition. Robots could go beyond reminding a patient to take medication and dispensing it to send a report to the doctor and even call an ambulance. But these innovations are still in the future, and not all of them will prove truly valuable after they are extensively tested. The time for them will probably come, but for now the agenda is to increase the effectiveness of online consultations and create devices that continuously monitor important vital signs of people with health problems. Because the traditional legal provisions do not take into account the distinctive features of telemedicine, there is a need to adopt new legislation to protect the rights and legitimate interests of legal entities engaged in telemedicine and to remove unjustified legal barriers to the use of telemedicine technologies.

A leading example for combining all the technological solutions in a single location is the Ontario Telemedicine Network (OTN), one of the largest telemedicine networks in the world. More than 28,000 people, including over 10,000 physicians, are members of its online service - the OTNhub which is a secure online environment that is home to several virtual care programs.

OTN's virtual service tools - secure video conferencing, remote monitoring, applications, and platforms - have great potential to influence and support important changes. This virtual assistance helps remove geographic, socio-demographic, and cultural barriers to help provide easier, smarter, and faster care. Collaborating with many partners, OTN continues to search, verify and implement virtual services and find options that solve key problems in the healthcare system.

OTN's goal is to improve the quality of patient care (modernizing access to services, developing special systems for chronically ill patients, improving home care systems). The goals described are closely connected with the 
main issues in the field of telemedicine, which OTN will raise at conferences during 2020 and 2021.

Other goals of the clinic, such as reducing the cost of services and reducing waiting times, are also indicative of general trends in telemedicine; they bear on improving how the clinic functions as a whole. Such changes increase the overall performance of the clinic. The important point here is that both kinds of challenges for telemedicine are being addressed within a single medical institution.

Of course, achieving these goals requires an immense effort that focuses on the entire ecosystem of the clinic, and this can happen only over a considerable length of time. One step in the process was taken back in 2018 and 2019 when OTN integrated more than eight different electronic systems.

Apart from plans and ambitions, OTN points to statistics that show the results of that integration in 2017 and $2018^{45}$ :

896,529 patient consultations;

21,498 video visits served to a patient's home;

570 million $\mathrm{km}$ in patient travel avoided;

$\$ 2,8$ million saved to date via Virtual Critical Care;

\$ 71,9 million saved in Northern Health Travel Grants.

All of these figures suggest what telemedicine can achieve. Of course, this is the most advanced telemedicine center in the world, and the success of telemedicine in general will be determined by opening more clinics of the kind or by its development throughout a particular region. But this is precisely the kind of system worth emulating. It covers all the health needs of the population even though it positions itself as a still developing treatment center.

\section{Current State of Telemedicine in Russia}

In Russia the impetus for implementing telemedicine came from the enactment of Federal Law No. 242-FZ dated 29 July 2017 "On amending certain legislative acts of the Russian Federation on the application of information technologies in the field of healthcare", which entered into force on 1 January 2018.

This law permits medical opinions, certificates, prescriptions for medicines and medical devices to be issued in electronic form, gives patients the

${ }^{45}$ OTN Annual Report 2017/18. Available at: https://otn.ca/wp-content/uploads/2017/11/otnannual-report.pdf (accessed: 29.04.2020) 
option to provide their informed consent to a medical intervention or refusal in electronic form, and establishes the legal basis for the creation and operation of information systems in healthcare.

The legislation of the Russian Federation also sets restrictions on the provision of remote telemedicine services to a patient. Patients cannot be diagnosed, nor can their treatment be prescribed or remote monitoring of the state of their health be set up without an appointment in person. Telemedicine technologies can be used only for the prevention, collection and analysis of patient complaints and medical history; assessment of the effectiveness of treatment and diagnostic measures; medical monitoring of the patient's health; making decisions on the need for an appointment in person (survey, consultation); in order to adjust previously prescribed treatment (parts 2-4 of the Federal Law No. 323-FZ dated 21 November 2011 "On basics of health protection of the citizens in the Russian Federation"). Online telemedicine services that operate in Russia, such as Yandex.Health ${ }^{46}$ and Telemed Doctor Nearby ${ }^{47}$, stipulate in their user agreements that only consulting services are provided to their clients and that they should contact a specialist in person in order to be diagnosed or have treatment prescribed.

Although remote consultation with a doctor is not the legal equivalent to a face-to-face appointment, significant steps have been taken for legally providing telemedicine. This law has laid the foundation for nationwide digitalization of healthcare in Russia. Electronic document management, healthcare information systems, remote monitoring of patients' health, identification and authorization of doctors and patients - these and other aspects of e-health have received regulatory support in the Russian Federation. In addition to that law, a number of by-laws and regulations have been developed building upon the foundations laid down by federal legislation (most of those regulations concern the establishment of the Unified State Health Information System). Nevertheless, developing telemedicine further will require solutions to a wider range of legal issues.

${ }^{46} \mathrm{f}$ doubtful qualitytives thanrte.agraph becaues dy long as was introduced as approach. esentniation byd when medications go onlin Terms of use of the Yandex.Health service. Available at: https://yandex.ru/legal/health_termsofuse/ (accessed: 29.04.2020)

${ }^{47}$ Telemed: Terms and conditions of use of services. Available at: https://telemed.drclinics.ru/ static/user_docs/terms_and_conditions/index.html (accessed: 29.04.2020). Based on the results of the consulting service, a medical report is drawn up - an electronic document compiled by the doctor containing the results of the medical consultation without arriving at or modifying the diagnosis and prescribing treatment. 
In Russia the expectation is that every ruble invested in prevention and treatment can save at least 3 to 7 rubles of expense to other sectors of the economy ${ }^{48}$. For example, labor productivity should increase while mortality and disability will decrease, and the economy as a whole will be stimulated. This is happening because healthcare supports and creates labor potential.

Russian medicine tends to be more personalized and less cursory than in other countries. Russian doctors do not immediately prescribe antibiotics for everyone with a cough regardless of the reasons for it or the age of the patient. This approach, which diverges from medicine in many other countries, has long been the established tradition in Russia.

Another aspect of Russia's distinctive way of practicing medicine is that doctors are often more sympathetic and "hands-on". On a first appointment with a doctor, a Russian patient can expect to be touched, poked, tapped and so on. Not all countries take this approach.

Another feature of Russian medicine that is far from universal is that medical care is provided to citizens free of charge. In the USA by contrast every request for medical assistance must be paid for personally or through an insurance policy. Insurance packages vary widely depending on the medical services included and their cost.

The overall availability of medicine will affect the availability of telemedicine as well. The more people are able to use its innovations, the more involvement will increase, and that will become a catalyst for further development of technology. People's involvement is always a kind of feedback; the greater it is, the more the technology will adapt to the needs of society. That adaption will help to entrench telemedicine's popularity.

Russia also provides free medical examinations. These clinical examinations consist of a set of procedures that include a preventive medical exam and additional examination performed in order to assess the patient's state of health and provided for certain groups of the population in accordance with the legislation of the Russian Federation.

Telemedicine would streamline part of the medical examination (for example, filling out questionnaires) by allowing it to take place online; the results could also be received online results and shared with the patient's

${ }^{48}$ Russia's share in the global plastic surgery market remains at 5\% (account of a press conference posted on the Russian Agency for Health Information). Available at: http://ria-ami. ru/2016/06/ekspert-dolya-rossii-na-mirovom-rynke-plasticheskoj-hirurgii-ostavlyaet-5/ (accessed: 29.04 .2020$)$ 
doctor. Expanding functionality in this way would also increase people's involvement in using telemedicine technologies.

The ability to quickly make an appointment with a doctor is very important to patients. If a Russian patient needs to see a specialist, they can sign up for a visit at any local hospital in the next few days. In other advanced countries, it would be unusual even to see a general practitioner so quickly. In the UK, the patient is examined first by a nurse, who decides whether the patient needs an immediate medical examination or whether they can return the next day to wait in the general queue.

How quickly medical services are provided will also affect the speed of response during telemedicine interactions. Telemedicine has the potential to expedite medical care online so that it is even faster and available at any time of day. The speed with which medical procedures already happen in Russia will be further accelerated by the kind of turnaround that telemedicine will enable. A patient should be able to order a medicine, begin taking it and share information about how the treatment is proceeding without leaving home.

What is called traditional medicine also has a place in Russian medicine as it does in some Asian countries. Although it may sound fanciful or frivolous to some, there is considerable evidence that many illnesses can be treated with the proper intake of natural ingredients. If the effectiveness of traditional medicine continues on its path to recognition, that will spur doctor-to-doctor exchanges about its applications; and telemedicine should be able to facilitate that process as Russian doctors tap into the clinical experience and trials of their colleagues practicing traditional medicine.

One last feature of Russian medicine that sets it apart is a personal approach to patients. In Russia's medical practices, standard treatment protocols are not always relied upon or regarded as sufficient. More often a very personalized approach is used in which all aspects of the patient and their body are taken into account.

Standards are in place to regulate what kind of examination a patient should have and what medications should be prescribed for them. But doctors in Russia frequently make a diagnosis in the absence of all the recommended test results and may prescribe medications that are not on the list of standard treatments (but according to the doctor are more suitable for a particular patient). The standard procedures here point out a certain path for treatment, which the doctor may not entirely follow. 
Of course, doctors must know the existing standards, protocols, procedures and clinical recommendations, but they may actually follow them or not depending on the clinical situation and their professional experience ${ }^{49}$. This kind of variability constitutes a challenge for digitalization and may delay its development to some extent. But with proper analysis and preparation of a compatible legislative base and regulations, this can become an advantage that will make Russian telemedicine stand apart from others by improving the quality of service while holding waiting times to a minimum and also taking the lead in developing and disseminating new technologies and kinds of treatment.

As telemedicine advances, all of this will become even more convenient. Patients will no longer have to visit the hospital many times to present their test results to the doctor; they will be able to make some measurements at home whenever convenient and then share the diagnostic results with a doctor just as conveniently.

One step along that path for telemedicine in Russia is the current development of the Unified State Health Information System (USHIS) ${ }^{50}$.

The National Center for Informatization (NCI) has developed the Federal Register of Electronic Medical Documents (hereinafter - REMD) as a subsystem of USHIS in order to organize the collection of data from information systems in the health sector available in electronic medical documents created by medical organizations. One of its tasks is to ensure a comprehensive and smooth transition by medical organizations from a paper-based medical workflow to an electronic one with a legal structure. This transition will expand the use of interagency electronic interaction.

Legally structured electronic document management in healthcare will eliminate the possibility of losing or mutilating medical records. Medical organizations and doctors will, under lawful conditions, gain access to all patient medical documentation and thus improve the continuity of medical care. In other words, Russia's USHIS is creating its own version of electronic health records and a system to manage them.

At this stage it would come as a surprise if telemedicine in Russia would lag behind the rest of the world. All the countries that have placed a high

49 The Code of Professional Ethics for a Doctor (adopted by the First National Congress of Doctors of the Russian Federation 5 October 2012). Available at: http://www.consultant.ru/document/ cons_doc_LAW_174773/ (accessed: 29.04.2020)

${ }^{50}$ Unified State Health Information System. Available at: https://egisz.rosminzdrav.ru/ (accessed: 29.04 .2020 ) 
priority on telemedicine as Russia has are at the stage of implementation, testing or debugging electronic medical records. Russia's position at the forefront of this process is confirmed by the data of the Future Health Index 2019 report $^{51}$, in which Russia's way of introducing telemedicine is regarded as a valuable template that can be followed by all countries in improving their healthcare systems.

The report repeatedly refers to Russia as a forerunner and among the leading countries in telemedicine, and it notes the results that Russia has achieved in the dissemination of technology. Russia, along with some developing countries (India, Saudi Arabia, China), exemplifies the way that technologies are increasingly becoming part of the everyday healthcare experience for both health professionals and patients.

Russia is among the top countries ranked by the percentage of medical workers who currently use some kind of digital healthcare technology or mobile healthcare applications. The most common commercial telemedicine services at present are:

Yandex.Health ${ }^{52}$ in which pediatricians, general practitioners, gynecologists, dermatologists, venereologists, gastroenterologists, neurologists, psychologists, pediatric psychologists, and cosmetologists make recommendations via chat or video links. They answer questions, create a medical record, and decrypt test results.

DocDoc (a project of Sberbank) ${ }^{53}$ with a website and an application for smartphones. The service allows users to get advice and make appointments for diagnostics or examinations.

DOC + service $^{54}$ is available as a website and a mobile application. It receives a doctor's recommendations, can place calls to a doctor at a specific address, make an appointment, enable testing or other procedures at home, and order medicines from a pharmacy.

Medved.Telemed ${ }^{55}$ is a system for remote consultation of doctors. In addition to the functionalities already described for the other services, this system has a convenient doctor interface that enables consultations and one-on-one chats.

${ }^{51}$ Ibid.

${ }^{52}$ Yandex. Health. Available at: https://health.yandex.ru/ (accessed: 29.04.2020)

${ }^{53}$ Docdoc service. Available at: https://docdoc.ru/ (accessed: 29.04.2020)

54 Docplus service. Available at: https://docplus.ru/ (accessed: 29.04.2020)

${ }_{55}$ Medved. Telemed system for remote telemedicine consultations. Available at: https://telemed. mis-region.ru/ (accessed: 29.04.2020) 
Qapsula ${ }^{56}$ is an interactive support system for improving the effectiveness of prevention and treatment of various conditions. In addition to the option to consult with a doctor in any convenient format, the project has a program with a chat bot for webOS, iPhone and Android. It monitors physical activity and physical parameters, reminds patients of appointments with their doctors and when to administer tests and take medications.

Robomed $^{57}$ is an even more complex information system that, in addition to the usual telemedicine functionality, assists clinics in their business operations. The system automates and organizes the processes of a clinic by modeling its business in order to adapt quickly to the ever-present changes. The system stores all patient data in a single electronic chart, tracks rates of change and sets up a complete patient management cycle.

Medesk ${ }^{58}$ automates a doctor's registry and workstation, online recording and telephone communications, cash flow and finances, warehouse and reporting, as well as more than twenty modules and extensions such as: online recording, registry, doctor's workplace, cash flow and finances, remote diagnostics, telephone communications, inventory accounting, and management reporting.

Other services such as Doctor Nearby, OnDoctor, Ok'Doctor, and Doctor Smart provide standard ways of consulting with a doctor.

Smartphone telemedicine applications in Russia as well as electronic devices for ECG, blood pressure measurements and various applications for chronically ill patients hold to the same standard of functionality as in other countries. Russia also has the Tyto Care apparatus that makes remote consultation more like a face-to-face visit.

Of course, not all the services now available will continue to advance and remain on the market. That depends to some extent on how telemedicine services develop. Will the doctor eventually have an option in the future to make a diagnosis and write prescriptions online? Will a patient be able to order medications at home?

Although telemedicine in Russia is relatively advanced in its pace of development, there are still problems that prevent those technologies from developing and penetrating faster. In a comparison of fifteen countries, Russians are among those who are most open to remote consultations as part of non-

${ }^{56}$ Qapsula personal assistant. Available at: https://qapsula.com/ (accessed: 29.04.2020)

57 Robomed: about product. Available at: https://robo-med.com/about/ (accessed: 29.04.2020)

${ }^{58}$ Medesk Medical Information System. Available at: https://www.medesk.net/ru (accessed: 29.04.2020) 
emergency care (55\%). However, less than $25 \%$ of medical workers currently use telemedicine for doctor-patient interaction in their clinic or practice.

Doctors are more willing to interact online with another health professional (58\% compared with the 15 -country average of $47 \%$ ) than with a patient ( $24 \%$ compared with the 15 -country average of $30 \%)^{59}$. The main goal of doctors now is to use telemedicine to consult among themselves; doctors are just beginning to involve patients in remote processes. This is logical enough: first debug operating within an organization and then connect with its direct consumers.

Medical workers do not yet use all the capabilities of AI technology. Russian doctors use AI mainly for administrative tasks: recruiting staff and scheduling patients $(70 \%)$, although the potential of AI is much greater when applied to telemedicine planning. AI has important uses in diagnosing patients, drawing up a treatment plan and recommending therapy. Here Russia is no forerunner when average AI use among the 15 countries surveyed is $45-47 \%$, as in Russia it varies from 40 to $46 \%{ }^{60}$.

Despite the relatively high rate of using new technologies to track patients' health indicators $(57 \%$ higher on average than in the 15 countries surveyed), $20 \%$ of patients do not exchange data with a doctor on an ongoing basis, and $50 \%$ of patients have never transmitted data to a doctor ${ }^{61}$.

Lack of access to information exchange systems hinders the development of telemedicine technologies, and this means that potential users cannot see much advantage in using this kind of system. Of course, many of the holdouts are also concerned about privacy and data protection. But the main reasons why medical workers do not transmit data outside a medical institution (only $28 \%$ do so, but $80 \%$ transmit data within a medical institution) are a lack of access to a data exchange system (69\%) and the lack of compatibility between different record-keeping systems $(55 \%)^{62}$.

Russian patients themselves note the importance of access to their medical data. Despite the fact that electronic medical records (EMR) are only $5 \%$ implemented, $68 \%$ of patients would like to have access to their data ${ }^{63}$. This indicates that providing Russian patients with access to their electronic medical records would improve public health.

${ }^{59}$ Future Health Index 2019. Report on Russia. Available at: https://www.philips.ru/c-dam/corporate/ru_RU/fhi/FHI_2019_Report_RUSSIA.pdf (accessed: 29.04.2020)

60 Ibid.

61 Ibid.

62 Ibid.

63 Ibid. 
Despite the ease of use of EMR, security concerns remain the main obstacle; and this reluctance in turn slows down introduction of new medical technologies in everyday life. About $30 \%$ of those who have not yet used these technologies claim that they will start using them if they are sure that their medical data will be secure ${ }^{64}$.

Table 1. SWOT analysis of the implementation of telemedicine technologies in medical organizations in Russia

\begin{tabular}{|l|l|}
\hline Strength & $\begin{array}{l}\text { 1. Unified storage system } \\
\text { 2. Instant access to patient information } \\
\text { 3. Consultation for patients with disabilities } \\
\text { 4. The possibility of early detection and diagnosis of patient conditions } \\
\text { 5. Convenience for patients } \\
\text { 6. Continuous monitoring of the health status of chronically ill patients } \\
\text { 7. Improving compliance through 24-hour doctor communication }\end{array}$ \\
\hline Weakness & $\begin{array}{l}\text { 1. Imperfect online diagnostic system (more details in section 3) } \\
\text { 2. Low technical literacy of employees at medical institutions }\end{array}$ \\
3. Low technical literacy of older patients \\
5. Difficulty in protecting patient personal data \\
6. Expensive equipment to ensure high quality data transfer (photos, videos) \\
to doctors \\
7. Uncertainty about online consultation fees
\end{tabular}

${ }^{64}$ Ibid. 
In the course of the research, the authors carried out a SWOT analysis was carried out to determine the current state of telemedicine in Russia. Table 1 presents the strengths and weaknesses of telemedicine as well as opportunities and threats to it. According to the results of the analysis, the goal of telemedicine should be "to make remote provision of medical services accessible and convenient."

In the course of the study, a survey was conducted of 264 medical staff (doctors, supervisors of doctors and deputies) at several medical institutions in Russia and in the city of Tomsk.

The questionnaire was provisionally divided into two blocks: an employee's experience in using telemedicine; and assessment of the outcomes of using telemedicine. The results of the questionnaire showed that telemedicine services were used by more than $80 \%$ of respondents.

Percentages of positive outcomes in using telemedicine are presented below (Fig. 4). The most positive is the ability to exchange experience with colleagues.

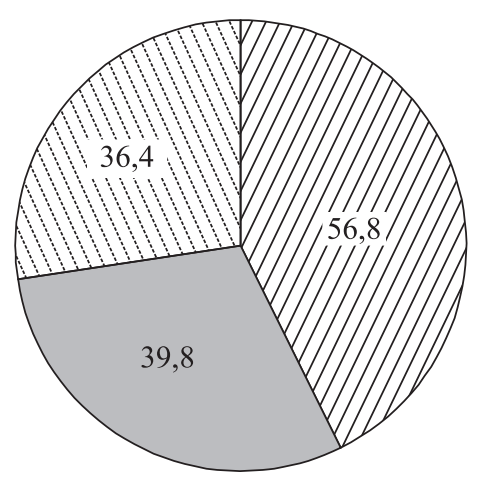

$\square$ Ability to exchange with colleagues

$\square$ Simplification of work (faster, more efficient)

Ability to conduct research on the data obtained

Fig. 4. Positive outcomes of using telemedicine

A part of the questionnaire addressed the best ways to use telemedicine (Fig. 5) and also difficulties in working with telemedicine technologies (Fig. 6).

The questionnaire showed that $80 \%$ of respondents use telemedicine technologies, but only $9 \%$ of them see any problems greater than system instability. That problem may prevent as much as $20 \%$ of the potential usage of telemedicine. 


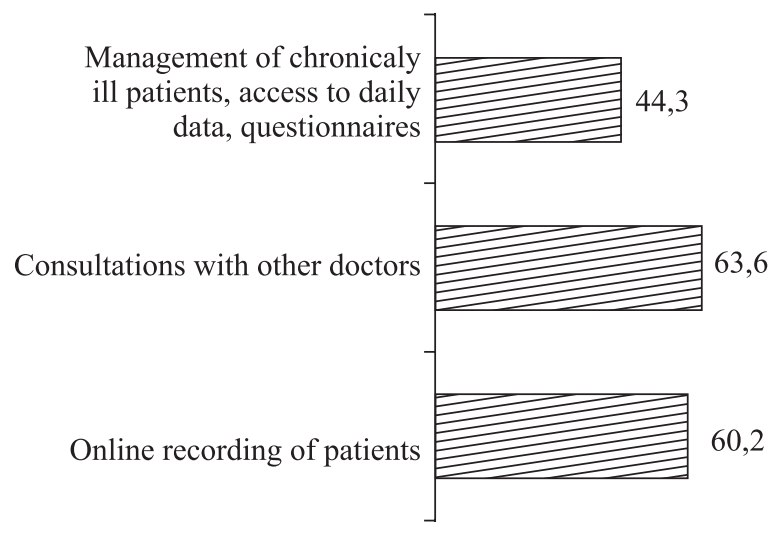

Fig. 5. The best ways of using telemedicine

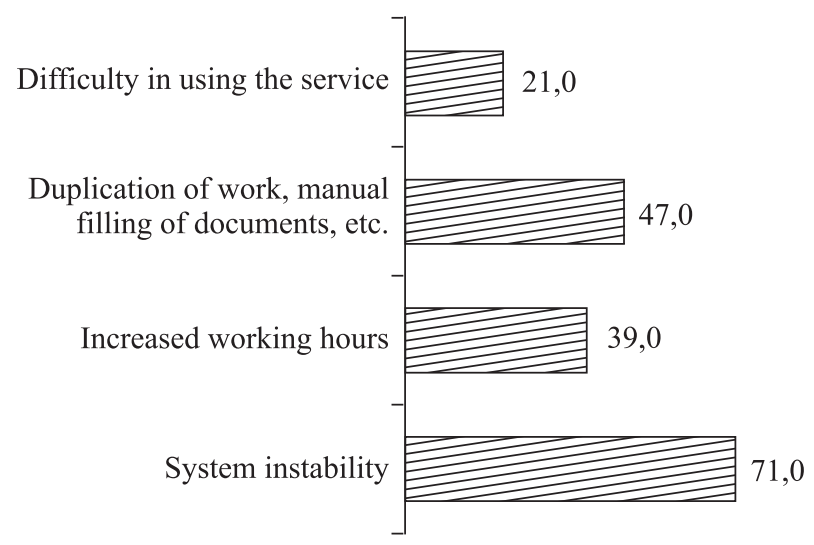

Fig. 6. Difficulties in working with telemedicine systems.

Despite the fact that $60 \%$ of respondents believe that telemedicine will increase the effectiveness of treatment (Fig. 7), medical personnel after the widespread introduction of telemedicine are apprehensive about increased work without increased wages and the likelihood that patient data will be leaked (Fig. 8).

These questionnaire results show that medical staff are generally ready to use telemedicine technologies.

During an interview one specialist respondent maintained that the development of telemedicine in Russia, more than in any other country, can and should be based on the long-standing traditions of layered healthcare, which has largely compensated for the negative effect of large distances and uneven development of regions with different population densities. 


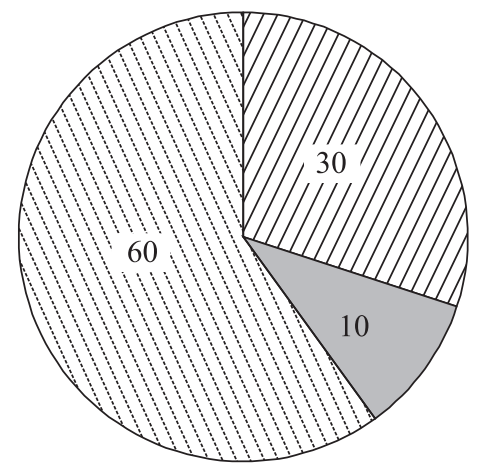

$\square$ An increase in the number of outpatient visits to a doctor

Reduction in the lenght of hospital stay

An increase in the effectiveness of treatment

Fig. 7. Positive effects of telemedicine

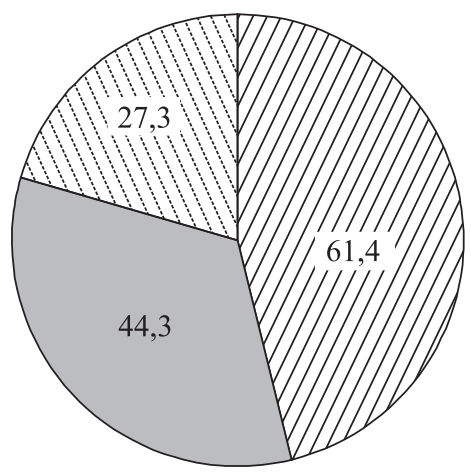

$\square$ Increased work without increased wages

$\square$ Likelihood that patient data will leak

Complexity of training in the use of thechnologies

Fig. 8. Apprehensions of medical staff about more penetration by telemedicine

The development of telemedicine can have a significant impact on all the functions of the healthcare system, including the development and coordination of medical science, disease prevention, emergency and planned care, training and advanced qualification for personnel, and allocating material and technical resources.

Another specialist commented that the development of information technology opens up another prospect for the future, which would stand alongside remote consultations. This is the goal of forming a single history of human illness. When treating the same patient, doctors communicate with each other using extracts, which are clearly not enough. And even if 
the patient has a consultation with the best possible specialist, all the data needed may still be lacking. In the future, when a unified medical telecommunication platform has been created, it would be realistic to arrange access to all of a patient's medical documents that are stored in various medical institutions for any location where those records are needed, including during telemonitoring of patients with special needs (physical disabilities, the elderly and others). In general, this task is much more complicated than arranging remote consultations, but it can be handled in stages.

These comments indicate that medical workers in Russia become quite ready to implement $\mathrm{AI}$ and other technologies into their usual processes once they understand how using them simplifies their work and they understand how to use them.

Unfortunately, the introduction of technologies in areas where doctors have always made decisions on their own (diagnostics, prescribing therapy, etc.) will take longer. Innovations of that kind will require a process of gradual familiarization and incremental experience in their use.

Patients are enthusiastic enough and are already using the new technologies at the same pace as doctors do for their administrative tasks (65-70\%). But, as the statistics of the report show, the health professional is the weak link in doctor-patient interactions. Healthcare staff see working with devices for constantly monitoring the state of health as something new, and they still have little experience in using those technologies. Although the percentage of patients using technology is quit high (compared to other countries), the data generated is not transmitted probably because doctors will not handle it properly. One solution might be to recognize the importance of educating medical staff in the use of new technologies and motivating them, possibly through bonuses.

Judging by statistics and the results of surveys, telemedicine is coming together like the pieces of a puzzle: the way patients and medical workers are beginning to use telemedicine technologies quite extensively counts as a piece or two in place, but the lack of interconnections for information exchange is a piece still missing. The importance of patient access to their medical data is supported by evidence that patients with access to their EMR are more proactive (9\%). And even those Russians who do not have access to EMR say they would like their doctor to have access to it when he is treating them. Patients are more likely to cooperate with medical workers when they have information about their health.

Doctors are beginning to use telemedicine, especially for doctor-to-doctor communication, but the development of doctor-patient telemedicine is 
hindered by those missing puzzle pieces: everyone understands what the benefits of using it can be, but how to build it, how to make it work, how to connect systems, and how to set up the correct exchange of data between medical institutions are all pieces yet to be found.

To fill in the missing pieces, it is important to analyze all the systems in operation and determine a protocol of interaction common to them all so that the system chosen by a medical institution does not prevent its interaction with others. This process will have to avoid creating artificial barriers, gather information about the interactions that need to take place, and analyze those interactions in order to determine new paths for telemedicine's future.

\section{Telemedicine vs CoVID-19: Challenges and Opportunities}

At a time when social distancing is one of the main ways to combat the COVID-19 pandemic, telemedicine is becoming a key technology for safe and effective communication. The World Health Organization has mentioned telemedicine ${ }^{65}$ among its core services in the policy brief "Strengthening the Health System: A Response to COVID-19." This new WHO policy indicates that, as part of optimizing service delivery, telemedicine should become one of the alternative models for providing clinical services and supporting clinical decision-making.

The COVID-19 pandemic has taken telemedicine to a new level. As healthcare providers must remain healthy, the need for remote technology has increased by an order of magnitude. The Center for Disease Control and Prevention (CDC) and $\mathrm{WHO}$ advocate using telemedicine to monitor patients and reduce the risk of spreading the virus through visits to hospitals. The Academy of Family Physicians ${ }^{66}$ and the American Medical Association (AMA) ${ }^{67}$ have

${ }^{65}$ Strengthening the Health Systems Response to COVID-19. Technical guidance \#1: Maintaining continuity of essential health care services while mobilizing the health workforce for COVID-19 response. Available at: https://euro.sharefile.com/share/view/sbc0659718fd4c8aa (accessed: 29.04.2020)

${ }^{66}$ Using telehealth to care for patients during the COVID-19 pandemic. Available at: https:// www.aafp.org/patient-care/emergency/2019-coronavirus/telehealth.html (accessed: 29.04.2020)

${ }^{67}$ Key changes made to telehealth guidelines to boost COVID-19 care. Available at: https:// www.ama-assn.org/delivering-care/public-health/key-changes-made-telehealth-guidelines-boostcovid-19-care (accessed: 29.04.2020) 
issued similar guidelines. The US government has also taken significant step $^{68}$ to expand telemedicine services.

The Centers for Medicare \& and Medicaid Services (CMS) in the US have expanded Medicare coverage for telehealth visits, the Office for Civil Rights (OCR) under the US Department of Health and Human Services (HHS) announced it will waive potential HIPAA penalties for good faith use of telehealth during the emergency. One other US institution, the HHS Office of the Inspector General (OIG), provided flexibility for healthcare providers to reduce or waive beneficiary cost-sharing for telehealth visits paid by federal healthcare programs.

There are also telemedicine initiatives apart from the US government, such as the Bergen-New Bridge Medical Center, specializing in telemedicine for COVID-1969. With their partner Air Visits, Bergen New Bridge Cares offers urgent-care remote screening and assessment by a licensed physician of patients who have medical complaints and symptoms. Telehealth consultations with an infectious disease physician are available if necessary.

In the EU countries there is an imbalance and shortage of medical work$\mathrm{ers}^{70}$ as well as unequal quality and access to medical services. The number of doctors varies from 1.9 in Turkey to 5.2 in Austria per 1,000 people ${ }^{71}$. The health workforce structure is changing ${ }^{72}$, as one in three doctors is over the age of 55 . This situation has become especially critical and has yielded dire results during the pandemic. Healthcare professionals who are in the forefront of the fight against the COVID-19 epidemic have the highest risk of infection. Telemedicine can help reduce this risk by minimizing face-to-face interactions.

${ }^{68}$ Secretary Azar announces historic expansion of telehealth access to combat COVID-19. Available at: https://www.hhs.gov/about/news/2020/03/17/secretary-azar-announces-historic-expansion-of-telehealth-access-to-combat-covid-19.html (accessed: 29.04.2020)

69 Bergen New Bridge Medical Center expand telehealth service for COVID-19. Available at: https://www.globenewswire.com/news-release/2020/03/03/1994551/0/en/Bergen-New-BridgeMedical-Center-Expand-Telehealth-Service-for-COVID-19.html (accessed: 29.04.2020)

70 Transformation of health and care in the digital single market - Harnessing the potential of data to empower citizens and build a healthier society. Available at: https://ec.europa.eu/health/ sites/health/files/ehealth/docs/2018_ehealth_infographic_en.pdf (accessed: 29.04.2020)

${ }^{71}$ Strengthening the health system response to COVID-19. Recommendations for the WHO European Region Policy brief available at: https://euro.sharefile.com/share/view/s5af6405658d4b0eb (accessed: 29.04.2020)

${ }^{72}$ Health Workforce. Data and statistics. Available at: http://www.euro.who.int/en/health-topics/Health-systems/health-workforce/data-and-statistics (accessed: 29.04.2020) 
Telemedicine can provide more choices of effective measures to combat COVID-19 for different categories of people in the following ways.

For self-isolated citizens: remote monitoring of health status, online consultation with a doctor, the ability to order medicines at home; and the possibility of using online questionnaires and consultations to determine the need for hospitalization and ambulances.

For patients in home treatment (chronically ill, patients with COVID-19 or other mild diseases that do not require a hospital): remote monitoring of the disease $24 / 7$ and monitoring of treatment by a doctor, online communication and video consultations.

And, of course, for doctors with mild symptoms of COVID-19: the ability to work with patients remotely and to consult doctors working in the hospital.

Special attention should be paid to staff training during the pandemic, especially for hospital recruits. This would include the ability to control information through a dashboard or automated matrix to assess the situation in real-time (with the ability to have a more experienced specialist intervene promptly in the treatment process), to create a plan for the incidence of disease (to simplify the control of the course of the disease), and to use of electronic textbooks and video broadcasts to bring new recruits up to speed.

The COVID-19 pandemic is a challenging test for all telemedicine solutions $^{73}$ as well as an opportunity to prove how reliable and flexible they are in the new environment.

Although telemedicine offers the many features and advantages already described, it has some drawbacks and associated risks. The first risk is of misdiagnosis because of the difficulty or impossibility of differentiating among diseases by relying only on patients' reports of their symptoms. In online consultations patients often cannot provide more than superficial and general symptoms that will be insufficient for detecting certain less obvious conditions. For example, if a parent informs their pediatrician that a child has a fever, a sore throat and a slight cough, then any treatment prescribed on that slim basis could be absolutely useless because no one has examined the child's mouth, throat, or skin. The symptoms would be consistent with a simple cold, but acute infections such as scarlet fever, measles, or diphtheria could not be ruled out and might prove fatal if not promptly diagnosed.

${ }^{73}$ COVID-19: A continuously evolving process that requires adapting by the hour. Available at: https://www.healthcareitnews.com/news/europe/covid-19-continuously-evolving-process-requires-adapting-hour (accessed: 29.04.2020) 
Without the proper treatment the situation may have become irreversible in as little as two days. Doctors can diagnose such diseases or prescribe treatment for them with maximum accuracy only after a comprehensive physical examination and seeing the results from the necessary tests.

Another risk of misdiagnosis is that a symptom may go unnoticed online. A patient's appearance including their complexion and body position can be very informative. For example, if there are complaints of abdominal pain, then palpation is necessary in addition to hearing the patient's account of their condition. One of the symptoms of appendicitis is pain felt in the right iliac region when the front abdominal wall is tapped with one's fingertips. A person without a medical education will not be able to tap in the correct way and may leave out some significant details. Even body position is sometimes informative, but a patient will not always be aware of changes in it. If the patient is aware of some changes, a doctor who is new to video consultations and is used to observing body position during a face-to-face physical examination without needing to ask may overlook that point and not ask about it online.

Allergic reactions to medications constitute another major source of risk. Even if the doctor has asked all the appropriate questions during an online consultation, the patient may not be aware of an allergy, especially one to a medication being prescribed for the first time. At an appointment in person, emergency medical care (up to and including resuscitation) can be promptly given to a patient undergoing an allergic reaction; after an online consultation that will not be the case.

The patient also may not provide a complete and reliable history, since they may not understand what exactly is happening and can easily to underestimate the seriousness of their symptoms or exaggerate it. It goes with saying that patients are unlikely to accurately diagnose themselves. Even a patient's readings from measuring and monitoring devices may be doubtful, and telemedicine presupposes that the data sent using those devices will be correct and verifiable. However, the accuracy of the measurements sent to the doctor remotely depends on the patient.

When doctors cannot make a definite diagnosis, patients are tempted to use telemedicine not to get a referral to a specialist, but instead to avoid a stay in the hospital by picking up hints about possible diagnoses and selfmedicating, which can cause patients a great deal of harm. The risks from self-medication are much greater in Russia because many medications that require prescriptions in the US or EU are available on-demand at any pharmacy in Russia. 
The delivery of medications is the final area of risk that should be noted. The main problem is with quality of the medications delivered and the storage conditions during delivery. For example, a trained specialist should handle thermolabile preparations in order to ensure their effectiveness and safety. Prescription medication delivery must also involve a pharmacy or pharmacist. It is quite possible that medications delivered remotely will be of doubtful quality (if proper storage conditions are not provided) or that slow delivery or high cost for prompt delivery will make the service unsuitable for many patients.

The unprecedented acceleration in the development of telemedicine that COVID-19 has brought about should have happened many years ago. A better telemedicine system would have protected countless high-risk people from exposure to the coronavirus. But it took a pandemic to drive the change.

For many years, the advance of telemedicine has been inhibited by the inertia of regulations that are failing to keep pace with the development of information technology. Of course, it is not advisable to enact legislative acts for regulating telemedicine technologies in haste. Rushing into legislation will affect its quality and can harm the telemedicine system by forcing it to develop in ways that may sacrifice some of its advantages. But the current situation should become a catalyst for legislation to better accommodate telemedicine.

Measures to adapt healthcare legislation to the challenges of COVID-19 were quickly put in place in the first weeks of the pandemic in Russia,

First, the remote sale of medications was legalized ${ }^{74}$. Pharmacies licensed in Russia can now sell over-the-counter preparations remotely once they obtain official approval of the oversight bodies for this type of sale. In addition, in an emergency situation and (or) when there is a threat of the spread of a disease that poses a danger to others, the Government of the Russian Federation can establish a temporary procedure for the remote sale of prescription medications (with the exception of narcotic and psychotropic drugs, as well as preparations with ethyl alcohol content of over 25\%) in additions to over-the-counter ones.

${ }^{74}$ Federal Law dated 3 April 2020 No. 105-FZ "On amending Article 15.1 of the Federal Law 'On information, technologies and the protection of information' and the Federal Law 'On distribution of medicines"'. Available at: http://www.consultant.ru/document/cons_doc_LAW_349322/ (accessed: 29.04.2020) 
Second, a bill was introduced in the State Duma of the Russian Federation that expands the capabilities of telemedicine during a pandemic ${ }^{75}$. Specifically, the bill establishes the right of the Government of the Russian Federation in emergency situations and (or) when there is a threat of the spread of a disease that poses a danger to others to establish the scope of medical care provided through telemedicine technologies. Russian law at present permits the use of telemedicine only for consultations on prevention and diagnosis and for monitoring a patient's health; it can also be used to decide whether a patient should be referred to a medical professional for an examination in person. At the same time, current law prohibits the use of telemedicine for an initial diagnosis and for prescribing treatment remotely.

It is noteworthy that the legislation expanding the use of telemedicine in Russia was being drafted before the pandemic, but progress was slow. The threat of COVID-19 instantly accelerated that process.

Changes in the health insurance system that explicitly included telemedicine services as covered expenses are another way to facilitate use of telemedicine in a pandemic. This path was followed by the US federal government with the announcement that it would waive restrictions on telemedicine services for the elderly under its Medicare insurance program. Some states in the USA have already passed laws requiring private insurance companies to reimburse the cost of telemedicine services on the same basis as conventional health services (parity private insurance coverage for telemedicine).

Nevertheless, optimal development of telemedicine cannot be assured with narrowly targeted or temporary measures. Standardization and comprehensive development of legislation is required, and this requires thorough analysis in order to determine which diagnoses can be made online and which require appointments in person. It is important to standardize the procedure for online consultations so that older doctors can quickly adjust to the new way of interacting with patients. This requires a sustained approach and will take some time.

Another deficiency in telemedicine that became obvious during the pandemic is the limited scalability of the system that was in place. This limitation became more acute because of the sharply increased demand for telemedi-

75 The Government of the Russian Federation may receive the right to establish the features and procedures for the provision of medical care in emergency situations and in the event of a threat of the spread of a dangerous disease, including using telemedicine technologies. Available at: http:// www.consultant.ru/law/hotdocs/61143.html/ (accessed: 29.04.2020) 
cine during the pandemic. The technology was not ready for such a heavy load because the pandemic had not been anticipated. Prior to COVID-19 telemedicine was expanding at a steady but rather slow pace in keeping with the modest progress in changing its legislative framework.

The main requirement for telemedicine in a pandemic is to accommodate an increase in within a few hours, not over several days. When there are so many new users, telemedicine solutions should be an easy-to-use tool and accessible through any user device: computers, smartphones, laptops and tablets. The ability to integrate digital medical devices with telemedicine solutions would be an important step forward.

Cloud telemedicine services are the most effective tools at present. But cloud technology is not completely reliable and is therefore only a forced and temporary solution. The main problem with relying on cloud technologies is that they cannot properly guarantee the security of the large amount of personal data they contain.

If a large-scale telemedicine infrastructure had been created earlier, new and existing services would not have been overwhelmed by the unprecedented increase in demand. PlushCare reports that the number of appointments has increased by 70\%; Amwell has confirmed that since the virus appeared in the USA in January, application use has increased by $158 \%$ nationwide and increased by $650 \%$ in the state of Washington ${ }^{76}$.

Although the risks described above clearly require a thorough assessment and preparation of the legislative framework, the need to develop telemedicine technologies and apply them broadly has become apparent. In less than ten years, the world has encountered diseases such as the MERS virus, Ebola, Zika, and COVID-19. The prevalence of COVID has clearly underlined the importance of telemedicine, and key stakeholders must adopt the technology and make it an integral part of the healthcare system. This will advance the agenda for expanding digital healthcare in general while also preparing better for a potential emergency. Training and experience in using telemedicine will allow us, as far as possible, to survive such epidemics by reducing the burden on medical staff and enabling them to promptly suppress outbreaks or to avoid their rapid emergence and spread.

The pace of development of telemedicine should not be halted or slowed down after the world comes to terms with the pandemic. Telemedicine

${ }^{76}$ Telemedicine struggles to be an option for everyone in the wake of coronavirus. Available at: https:/qz.com/1821549/telemedicine-faces-unprecedented-demand-in-the-wake-of-coronavirus/ (accessed: 29.04.2020) 
should not be merely a temporary solution which falls short of its full potential and will not be ready to handle the next emergency. If that is allowed to happen, we can expect hospitals and doctors to be overloaded once again. The savings in time and the flexibility provided by telemedicine tools will benefit patients who are uncomfortable with visiting a doctor and also chronically ill patients who may experience panic, disorientation and trauma during transportation to a medical facility. The risk of contracting an infection while visiting a hospital will still be there after the pandemic.

This crisis gives us an opportunity to reorient healthcare and has shown everyone affected the convenience and potential of telemedicine.

\section{The Future of Telemedicine in Russia: Integration, Data Analysis, and Personalization}

Russia must first put the pieces of its telemedicine puzzle together by establishing communication and data transfer between medical institutions. Integration will be the first requirement for the future development of telemedicine.

Integration involves connecting the maximum number of providers and users of medical information to a unified system with both private and public healthcare organizations linked to it. The way electronic documents are managed in telemedicine should permit other organizations involved in research and developing innovative healthcare solutions along with others to connect to a single information system. Further integration of information systems and the involvement of new organizations in it will increase the availability, completeness and reliability of information about the health of the population.

In order for telemedicine to provide all the benefits claimed for it, medical workers should find that it eases their workload without introducing complications, Therefore integration should include electronic medical records (EMR), medical information systems (MIS), telepresence. and integration of data from mobile applications and patient devices.

EMR includes detailed documentation of visits, and their integration will prevent losing records and make the documentation more accessible to both doctors and patients. This will allow telemedicine to improve coordination of care and patient outcomes. It is also convenient for the patients themselves. With access to EMR, they can easily collect the necessary documents on the history of their condition at the request of a new or different doctor. 
MIS is integration between different medical information systems (MIS) within the same medical institution or between different ones. This will allow sharing data quickly and make doctor-to-doctor interactions more productive by exchange of the results of clinical trials and other important statistics. The patient will no longer have to locate paper records of tests and other documents; they can be confident that their doctor will already have access to all the necessary data.

Telepresence and rehabilitation robotics refer to a whole range of technologies that multiply the effectiveness of medical professionals by letting them interact with patients who are elsewhere. This technology can be used, for example, for concussions or other diseases that require constant monitoring: a robot can monitor the patient's behavior, notify medical personnel of significant changes and send alerts to a medical officer or doctor. The patient's condition is continuously monitored, but the doctor can deal with other patients in another place.

The final piece of the integration puzzle brings in data from mobile applications and patient devices. This is especially valuable for chronically ill patients whose state of health can be constantly monitored. Many patients with diabetes, for example, must now manually transfer data to the doctor by sending complicated tables or files in formats which differ depending on the program and device. In addition to the inconvenience for patients, this reduces the efficiency of doctors because data analysis takes more time. Statistical analysis, if it can be done at all, is also more difficult than it would be with comprehensive integration of patient data into the physician's system so that all data is stored in EMR.

Of course, telemedicine has some definite limitations: doctors cannot conduct all diagnostic measures only by remote means. But modern technologies such as Tyto Care are making remote visits to a doctor as much like appointments in person as possible.

The integration that goes beyond the different systems used by medical institutions to incorporate applications for patients and various devices will permit continuously gathering vital data and monitoring a patient's health in a much more effective way, and it will be useful for some kinds of prevention.

Data collection and analysis stand out among the new possibilities for telemedicine that integration opens up. The concentration of the most complete amount of information about the health status of the population, preferably in a fairly structured form ${ }^{77}$, will benefit from modern methods

77 Existing cognitive technologies are already capable of working quite effectively with unstructured information; however, the more structured data is processed, the more accurate are the results of their processing. 
of data analysis. Realization of this potential of electronic document management in telemedicine will make it possible to conduct minutely targeted medical research and process large amounts of medical information for socially significant purposes, which is a priority in building a digital economy in Russia and abroad.

Ensuring the mobility and responsiveness of data processed in health information systems is also necessary to maintain constant and ubiquitous access to relevant health information. For these purposes, it is important to ensure the technical compatibility of information systems with various types of devices, as well as to create opportunities for regularly updating information stored in these systems. These requirements are especially important in the dynamic monitoring of the health status of patients as dynamic monitoring is carried out by different devices. The information received from such devices needs to be synchronized, both between them and with information stored in information systems. At the same time, dynamic observation is useful for promptly taking emergency measures whenever necessary. Without constantly updating data in information systems, it is impossible to respond proactively to changes in the health status of patients. Of key importance in the legal provisions for the mobility and responsiveness of medical data are standards, technical regulations and other ways to unify the technical characteristics of medical devices and data processing.

Many companies such as Yandex. Health note that the motivation for large players to create telemedicine companies is not so much to add to their earnings by enabling remote consultations but rather to collect and analyze data. Yandex maintains that, after collecting millions or tens of millions of results from consultations or medical histories, processing technologies (such as AI) will make it possible to predict the course of diseases, the speed of recovery, and the reactions of a particular patient with a certain dataset to a prescribed medication.

This kind of analysis will take medicine to a completely different level. For example, it will be possible to use digital patient-oriented technology, as is done at the Teknon Medical Center in Spain ${ }^{78}$. When using it, doctors carefully examine each patient and build a 3D model; they can then compare the patient's indicators with those from the existing database in order to objectively choose the best treatment technique and avoid medical errors.

Data collection will also enable technologies that track patient compliance. Compliance is the degree of correspondence between the patient's be-

\footnotetext{
${ }^{78}$ Available at: http://www.teknonbarcelona.com/en/hospital (accessed: 29.04.2020)
} 
havior and the recommendations received from the doctor. This is an important issue for medicine in general, and doctors are making attempts to predict compliance, although it is very difficult to do this on their own. The more data there is to process, the more possibilities it will generate.

If we attempt to foresee what telemedicine will become over several generations (and not over a one-year horizon), then in this future we might reasonably expect that patients will be able to find out their prognosis for inherited illnesses and a recommendation of the most suitable treatment. The earlier a disease is diagnosed, the easier and faster it can be cured or prevented. With better knowledge about susceptibility to diseases, better measures could be taken to prevent them.

Therefore, data analysis will make telemedicine as personalized as possible and select the treatments that are most likely to work for a particular patient. In the past doctors would arrive at treatment plan for a patient based on the results of detailed questioning that went beyond the immediate effects of the disease to inquire about the patient's way of life, career and family history as a supplement to a thorough physical examination and the targeted use of measurements and laboratory tests. The integration of data with patient applications and devices feeding in analyzed information about the course of any of a patient's diseases throughout their life will make that process many times faster and more accurate. This is especially important for cancer, cardiovascular diseases, and metabolic diseases, that is, for those diseases that have the greatest negative impact on health and life expectancy.

Personalized medicine is the most valid way to construct a plan for examining and treating a patient, predicting the course of a disease, determining the effectiveness and possible side effects of medications, and also for selecting personalized treatment regimens, such as the chemical or biological products that are best for reaching molecular targets like the cell receptors of a particular tumor in a particular patient [Bodiroga-Vukobrat N. et al., 2016: 6].

Robust ways of processing information (collection, storage, transmission, etc.) will be needed to realize the potential advantages of telemedicine. Information in telemedicine can be collected from various sources and even without the direct involvement of a person through sensors and other devices through what is called "machine-generated data" [Drexl J., 2016]. It can have both a structured and unstructured form, be stored in different formats, and processed by different persons and organizations for various purposes. The lack of a unified technical, organizational and legal foundation for processing medical data in health information systems is a signif- 
icant barrier to information exchange and the successful development of telemedicine.

The key modern legal challenges for the development of telemedicine are information security and the protection of personal data.

E-health is one of the areas most prone to cyberattacks. For example, in the Australian Notifiable Data Breaches Report for 2018, the largest number of cybersecurity incidents among all vulnerable areas was recorded in healthcare [Burke W. et al., 2019]. Statistics show a rapid increase in the number of cyberattacks on health information systems worldwide, and the total damage from incidents for the industry is measured in billions of US dollars. According to a global study by Cybersecurity Ventures in 2017, between 2015 and 2017 the number of fraudulent cyberattacks in the healthcare sector increased 15 times, and it will probably increase another 4 times in $2020^{79}$.

The main kinds of cyberattacks on medical facilities are infection with malware and hacking employee accounts ${ }^{80}$. In Russia there has been an increase in the number of internal leaks of medical data due the negligence of employees at medical institutions ${ }^{81}$, and this underlines the need to defend against both internal and external threats to data security.

To ensure information security in telemedicine, it is important to verify that medical equipment and the devices (medical devices) and applications (software) used to transfer information between nodes of telemedicine services and the processing of data are also protected. Data security should be a top priority in applying the "internet of things" to medicine, perhaps through devices implanted in the human body that would make up an "internet of people" [Burleson W. et al., 2014], whose architecture still requires additional solutions for information security [Sicari S. et al., 2017: 39-74].

To increase the information security of medical devices, the principles of built-in security [Babar S. et al., 2011: 1-5] and privacy by design [Demetrius K., 2014] should be applied, taking into account the risks of violating the integrity and confidentiality of information and also incorporating mechanisms to counter these violations as the technical architecture of the products is designed and built [Purtova N. et al., 2015: 61]. These principles

79 Global Ransomware Damage Costs Predicted To Exceed \$5 Billion In 2017. Available at: https:// cybersecurityventures.com/ransomware-damage-report-2017-5-billion/ (accessed: 01.10.2019)

${ }^{80}$ Actual cyber threats. Q1 2019. Available at: https://www.ptsecurity.com/ru-ru/research/analytics/cybersecurity-threatscape-q1-2019/ (accessed: 29.04.2020)

${ }^{81}$ The number of domestic leaks of medical data has risen sharply in Russia. Available at: https:// www.osp.ru/medit/2018/08/13054369.html (accessed: 29.04.2020) 
should be considered when developing standards and technical regulations and in preparing technical specifications for product development, etc.

Ignoring the problems of information security cancels out all the advantages of telemedicine technologies because the degree of information security will determine people's trust in the new technologies and their willingness to pass an extremely important part of their lives into the "hands" of computers, communication networks, information systems and algorithms. The physical security of patients ultimately depends on information security in telemedicine. Only high standards of information protection and a reasonable balance between public and private interests concerning information can legitimize the use of new technologies in healthcare.

The bulk of the information processed in telemedicine is information about individuals, which makes it necessary to comply with the requirements for the protection of personal data when processing it. Moreover, such information is mainly personal health information, the processing of which is subject to even more stringent legal requirements. The requirements for processing personal data protect the right to privacy, but they also act as restrictions on the widespread use of telemedicine technologies for various purposes including in medical research.

Addressing issues in processing personal health data for research purposes, as well as issues in the legal system for handling anonymized personal data, should have a high priority because the options and conditions for using medical data in the digital economy and consequently the potential level and paths of development in e-health depend on the market for telemedicine services.

Legal regulation of personal data processing (including medical data) for research purposes is a problem both in Russia and in other countries. EU countries have made attempts to set conditions that allow more liberal processing of personal data for research purposes (Sjöberg C., 2017), and the problem was raised during the development of EU Regulation 2016/679 (GDPR).

The new European regulation establishes a broader basis for processing sensitive personal data without the consent of the subject. In particular, that data can be processed when it is serves a significant public interest as identified in the legislation of the EU and EU countries (paragraph 2(g) of Article 9 of the GDPR); in the provision of medical care, management of the healthcare system and healthcare services (paragraph 2(h) of Article 9); for the realization of public interest in healthcare (paragraph 2(i) of Article 9); and for the purpose of scientific, statistical research (paragraph 2(j) of Article 9). Also, 
paragraph 4 of Article 9 of the Regulation allows EU countries to establish in national legislation other conditions for processing personal health data.

These new foundations were reflected in the Regulation in response to the needs of the digital age and in connection with advancing information processing capabilities such as ways of processing Big Data and machine learning. The codification of valid grounds for processing special categories of personal data without the consent of its subject, as conceived by the developers of the Regulation, should contribute to a more efficient use of data for socially useful purposes. The fundamental rights and freedoms of the subject of personal data when processing their data is justified on these grounds should be ensured by observing organizational and technical data protection measures and ethical standards. Processing of personal data about state of health for scientific or statistical purposes should comply with the principle of minimization (Article 89(1) of the GDPR). If the goal of data processing is attainable without identifying its subjects, then measures must be taken to anonymize or pseudonymize data so that processing does not diminish the essence of the right to protect personal data, and it must be carried out with the adoption of measures to protect the fundamental rights and interests of the personal data subject.

Russian legislation on personal data permits processing personal data for statistical or other research purposes without the consent of the personal data subject only for ordinary personal data and only subject to their depersonalization. With regard to special categories of personal data, which include health data, processing for statistical and other research purposes is possible only with written consent, regardless of the depersonalization of data. It seems advisable to extend permission to process those special categories of personal data for statistical and other research purposes on a similar depersonalized basis. That would require clearly defining the depersonalization of personal data which makes processing personal data without consent permissible. Accreditation of data operators or processors and enforceable ethical standards for data processing are additional ways to safeguard the interests of personal data subjects

\section{Conclusion}

Although telemedicine is developing and regulated differently in each country, there are some common trends: the collection and analysis of medical records and patient histories; devices and systems to simplify commu- 
nication between doctors, home-use devices for chronically ill patients; and efforts to increase the effectiveness of online examinations.

Telemedicine also has obstacles to development common to all countries: a country's culturally determined attitudes, legislative barriers, distrust of new technologies, and incompatibilities in information systems.

A key development trend for telemedicine globally is EHR. And there are a number of sound reasons for this: data on the patient's condition are stored in a safe place, contain a history of changes in the patient's body throughout their lives, and systematize all information; this enables the implementation of particular programs to monitor the quality of healthcare in a country.

Because traditional legal provisions do not take into account the distinctive features of telemedicine, new legislation must be enacted to protect the rights and legitimate interests of legal entities in telemedicine and remove unreasonable legal obstacles that impede the use of telemedicine technologies. How long those legislative changes will take and whether they will keep pace with the development of telemedicine remains an open question.

Russia is no exception in its adjustment to telemedicine: it has its own characteristic medicine and telemedicine, but legislation is more an obstacle to development than a catalyst. Once the legislative issues are resolved, Russian telemedicine should reach a new level because of its special features: free medical care and medical examination, rapid availability of appointments with doctors, access to medicines, acceptance of alternative medicine, and a personal approach by health professionals.

The COVID-19 pandemic may be acting as another kind of catalyst for telemedicine because social distancing is one of the main measures used to combat it. Telemedicine fits in as a key technology for safe and effective communication concerning diagnosis, treatment and monitoring. The world is now considering the benefits of telemedicine that it previously neglected. Of course, telemedicine has its risks and disadvantages, but its usefulness in combatting a pandemic are undeniable.

Survey results showed that in Russia medical workers are ready to implement AI and other technologies in their usual workflow, provided that they understand how this simplifies their tasks. And patients in turn are ready to use new technologies and already are using them to about the same extent as doctors do (65-70\%).

Judging by statistics and the results of surveys, telemedicine is developing like pieces in a puzzle: various providers, patients and medical workers are beginning to use telemedicine technologies quite frequently, but the interconnections for information exchange have not yet been set up. 
In order to assemble all the pieces of the puzzle, it is important to analyze all the systems in operation and determine a protocol of interaction common to all of them so that the system chosen by a medical institution does not interfere with its interaction with others. This will prevent creating artificial barriers, and at the same time the data collected on interaction and its analysis can point the way to new paths for the development of telemedicine.

For many years telemedicine was held back by regulations that failed to keep pace with the rapid development of information technology. But now it is very important to resist the urge to hastily draft legislative acts for regulating telemedicine as a response to an emergency; what is needed is a sound legislative framework for telemedicine on an ongoing basis. Otherwise, the rush to legislate may result in regulations of low quality, which may impair the telemedicine system by forcing it to develop along lines that prevent it from providing all its potential benefits.

The pace of development of telemedicine should not be halted or slowed down after the world comes to terms with the pandemic.

This article is an attempt to discern the future for telemedicine in Russia and has identified key areas in it: integration, data analysis, and personalization. These development paths will open up completely different possibilities for using telemedicine: it will be possible to analyze data and use the analysis to predict any disease of any person for their whole life. That kind of forecast will make it possible to prevent the occurrence of a disease rather than combat it after it has taken hold. The population will be healthier and therefore more productive, which will certainly have a positive impact on the well-being of the country as a whole.

\section{D国 References}

Babar S. et al (2011) Proposed embedded security framework for Internet of Things (IoT), 2nd International Conference on Wireless Communication, Vehicular Technology, Information Theory and Aerospace \& Electronic Systems Technology (Wireless VITAE), Chennai, pp. 1-5.

Bodiroga-Vukobrat N. et al (2016) Personalized Medicine. A New Medical and Social Challenge. New York: Springer, 278 pp.

Burke W. et al (2019) Cybersecurity Indexes for eHealth, pp. 1-8. Available at: https://www.researchgate.net/publication/330371852_ (accessed: 01.10.2019)

Burleson W. \& Carrara S. (eds.) (2014) Security and Privacy for Implantable Medical Devices. Berlin: Springer-Verlag, 205 p. 
Carlisle G., Whitehouse D. \& Duquenoy P. (eds.) (2013) eHealth: Legal, Ethical and Governance Challenges. New York: Springer, 396 pp.

Currie W. \& Seddon J. (2014) A cross-national analysis of eHealth in the European Union: Some policy and research directions. Information \& Management, vol. 6, pp. 783-797.

Davis K. et al (2014) Mirror, mirror on the wall. How the performance of the U.S. health care system compares internationally. Available at: http://www.commonwealthfund.org/ /media/files/publications/fund-report/2014/jun/1755_davis_ mirror_mirror_2014.pdf (accessed: 01.08. 2019)

Demetrius K. (2014) Privacy-Invading Technologies and Privacy by Design: Safeguarding Privacy, Liberty and Security in the 21st Century. Berlin: Springer, $338 \mathrm{pp}$.

Drexl J. (2016) Designing competitive markets for industrial data: Between propertisation and access. Max Planck Institute, Research paper no 16, 70 pp.

Flodgren G. et al (2015) Interactive telemedicine: effects on professional practice and health care outcomes. Cochrane Database of Systematic Reviews, issue 9. Art. No.: CD002098. DOI: 10.1002/14651858.CD002098.pub2/ Available at: https://www.cochrane.org/CD002098/EPOC_interactive-telemedicine-effects-professional-practice-and-healthcare-outcomes) (accessed: 12.05.2020)

Moy F.et al. (2019) Techniques of monitoring blood glucose during pregnancy for women with pre-existing diabetes. Cochrane Database of Systematic Reviews, issue 5, CD009613. DOI: 10.1002/14651858.CD009613.pub4. Available at: https://www.cochrane.org/CD009613/PREG_methods-monitoringblood-glucose-pregnant-women-diabetes-improve-outcomes (accessed: 12.05.2020)

Oliveira T., Branquinho M. \& Gonçalves L. (2012) State of the art in telemedicine. Concepts, management, monitoring and evaluation of the telemedicine program in Alentejo. Studies in Health Technology and Informatics, vol. 179, pp. 29-37.

Purtova N.N., Kosta E. \& Koops E. (2015) Laws and regulations for digital Health. In: S. Fricker et al (eds.) Requirements Engineering for Digital Health. Berlin: Springer, pp. 47-74.

Putilo N.V. \& Volkova N.S. (2018) Telemedicine: Societal Needs and Possibilities of Legislation. Zhurnal rossiyskogo prava, no 6, pp. 124-135 (in Russian)

Sicari S. et al (2017) A policy enforcement framework for Internet of Things applications in the smart health. Smart Health, September 2017, pp. 39-74.

Sjöberg C. (2017) Swedish Proposal for Research Data Act. Paper presented at XXXII Nordic Conference on Legal Informatics. Available at: http://www.jus.uio. no/ifp/om/organisasjon/seri/arrangementer/2017/sjo\%CC\%88berg.pdf. (accessed: 29.04.2020) 
Wernick A. \& Klünker I. (2019) Prohibitions on long distance treatment: Historical roots and continuities in limiting the use of electronic telemedicine. In: T. Bächle \& A. Wernick (eds.) The Futures of eHealth. Social, Ethical and Legal Challenges. Berlin: Humboldt Institute for Internet and Society, pp. 169-177. Available at: http://doi.org/10.5281/zenodo.3297377 (accessed: 12.05.2020) 